\title{
Supplier portfolio selection based on the monitoring of supply risk indicators
}

\author{
Samira Mokhtar ${ }^{\text {a }}$, Parisa A. Bahri ${ }^{\text {a*}}$, Sorousha Moayer ${ }^{a}$, Adrian James ${ }^{b}$ \\ ${ }^{a}$ School of Engineering and Information Technology, Murdoch University, Perth, Australia \\ ${ }^{b}$ School of Energy and Resources, University College London, Adelaide, Australia \\ *Corresponding author.E-mail: s.mokhtar@murdoch.edu.au
}

\section{ABSTRACT}

This paper introduces a dynamic optimisation model for a manufacturer's optimal selection of a portfolio of suppliers. The model uses a set of indicators that measure risks imposed by suppliers on the manufacturing supply chain. These indicators measure financial stability, production stability, product quality and cost of suppliers. The model uses a combined simulation-optimisation framework to select suppliers and allocate orders to them based on real-time monitoring of supply risk indicators. This model uses a multi-period order allocation approach based on the viewpoint of a manufacturer in a manufacturing supply chain system. A system dynamics model simulates the interrelations and feedbacks among parties in the supply chain, i.e. suppliers, the manufacturer, and the manufacturing product market. It models the effect of supply risk indicators on a manufacturer's profit over a planning horizon. The result of the simulation is fed to a portfolio optimisation model to determine an optimal supplier order allocation based on the manufacturer's propensity for risk. The model informs the manufacturer to rebalance its supply portfolio in response to early changes in supply risk indicators over a planning horizon. The results show that supplier portfolio selection based on this framework provides higher expected profit and less risks to the manufacturer over the planning horizon. For instance, in our numerical example, the high-level risk averse decision maker made a profit of $5.4 \%$ and a risk of $1 \%$ less than those of low-level risk averse decision maker at the end of the planning horizon.

Keywords supply risk management, supplier selection, portfolio optimisation, system dynamics simulation, supply risk indicators 


\section{Introduction}

The supply chain of manufacturing processes is vulnerable to disruptions from unexpected events triggered by external and internal causes. External disruptions - often caused by natural disasters, economic downturns, cyber-attacks, devaluation of currencies and geopolitical changes - are mostly beyond the control of supply chain management. Internal disruptions influence the transactions among parties involved in a supply chain system and include a sudden change in cost, quality, timing and logistics performance. A supply chain system comprises several interconnected parties taking a product or service from the suppliers of raw materials, through manufacture, to final delivery to customers. The extent and complexity of such interconnections can increase the vulnerability of the supply chain system to external and internal causes of disruption. A disturbance limited to a party within a supply chain can propagate to other nodes of the system leading to major disruption and losses for the entire supply chain of a product. For instance, in 2016, Samsung Electronics had to recall a smart phone product due to technical problems with the defective batteries procured from a supplier; Samsung Electronics incurred a loss of $\$ 3$ billion [1]. Mobile phone manufacturer Ericsson lost $€ 400$ million after their supplier's plant caught fire in March 2000 [2].

Operational disturbances affecting the suppliers of raw materials, parts, or components, can expose a manufacturing supply chain to substantial risks. These disturbances include production instability, poor quality, financial instability, and increased supply cost. A manufacturer may take actions to control its exposure to such risks. For instance, to mitigate such supply risks, a manufacturer may expand its supply network and procure raw materials from several suppliers. It may also stock an inventory of raw materials for use in case of supply disruption. The timely action of a manufacturer is also of importance. A manufacturer can avoid risk or at least mitigate its effects by forecasting the occurrence of a disruption event. It enables the manufacturer to take appropriate actions before a major disruption occurs. A manufacturer's action to control its risk exposure; however, has overarching effects on suppliers' operation. For instance, in response to the poor performance of a supplier in terms of quality 
of raw material delivered, a manufacturer may reduce its order from the supplier and replace it with another supplier. This response can make the affected supplier more vulnerable to financial risks and cause further reductions in the quality of the supplied product. Reinforcing feedback between the supplier and the manufacturer creates a trade-off for the manufacturer's risk management actions. This feedback loop can expand to other parts of the supply chain, including the final product market (e.g. in the form of declining demand), other suppliers (e.g. in the form of additional requirements), and competitor manufactures (e.g. in the form of increasing market share).

To successfully manage supply risks, a manufacturer can develop a set of supply risk indicators for continuous monitoring. This would allow a manufacturer to evaluate the operational status of its suppliers including production and financial instability, quality performance, and cost. Tracking the supply risk indicators enables a supply chain manager to better forecast a supplier disruption and availability [3]. A manufacturer continuously monitors such indicators in real time to investigate the effects on other components of the supply chain system, including the manufacturing product price, quality, manufacturing product demand, and consequently manufacturer's profit and risk.

The decision maker determines the allocation of orders to suppliers to maximise its profit and minimise its risk. They, however, should undertake more risk to increase their expected profit and the optimal decision is made by reaching a balance between profit and risk. This expected profit-risk balance depends on the decision maker's degree of risk aversion. For example, the decision maker can increase its expected profit by choosing to source more of its supplies from suppliers with lower costs and quality. However, this decision can reduce the manufacturer's profit in the subsequent periods, because a low cost and quality supplier has typically lower financial and operational stability. The manufacturer may also lose its market share due to the production of low-quality manufacturing products. There is, therefore, a trade-off between manufacturer's expected profit and supply risk. A higher expected profit is typically driven by taking more risk. 
There are several models in the literature to consider the profit risk balance for allocating orders to suppliers. This paper develops a supplier selection and order allocation model considering the effects of supply risk indicators on supply cost and product market demand, and consequently on manufacturer's profit. The supply risk indicators are defined based on the supplier's product price, financial and production stability, and quality. The model also considers how a decision maker's risk propensity affects a manufacturer's profit and risk over a planning horizon. The model is based on the perspective of a manufacturer receiving supplies from several suppliers. A system dynamics model captures the dynamic relation between system variables to forecast the effects of supply risk indicators on manufacturer's profit over a planning horizon. The main reason for applying system dynamics is to simulate the complex interrelations among supply chain components in an understandable and tractable way, particularly to decision makers. System dynamics provides a flexible way to better understand how the complex system and its inputs work with various scenarios. The development of system dynamics involves decision makers in the modelling process by using a wide range of 'what if' scenarios under system uncertainties. The results of system dynamics are used in a portfolio optimisation model. Subject to decision maker's propensity for risk, portfolio optimisation enables the decision maker to determine the optimal order allocation among numerous allocation possibilities.

The remainder of this paper is organized as follows. Section 2 provides a review of the most relevant literature. Section 3 , explains the modelling of the supplier selection and order allocation framework employed in this paper, including the description of the system dynamics simulation and portfolio optimisation model. Section 4 provides a numerical example and a comparative discussion of the outcomes over three periods to investigate the impact of supply risk indicators on supplier order allocation. The main findings of the study are conveyed in Section 4 . The validation and limitations of the model are presented in $\underline{\text { Section } 5}$. 


\section{Review of literature}

The literature on supplier selection and order allocation is numerous; several studies [4-6] have reviewed the body of literature. Other studies $[7,8]$ have reviewed the effect of uncertainty on supplier selection and order allocation. To maintain our focus, we review the literature that studies supply risk indicators and the effects of decision makers' risk propensity on order allocation decisions over a planning horizon. This review is divided into three sections. Section 2.1 presents a review of studies that have explained the significance and application of supply risk indicators for managing a supply chain exposed to several risk sources. This section also explains other studies that have explored a decisionmaker's propensity for risk in supplier selection. Given the method applied in this paper, Section 2.2 presents a review of the application of system dynamics modelling and portfolio optimisation in supplier selection problems. Section 2.3 discusses the contribution of this study.

\subsection{Significance and application of supply risk indicators and risk propensity in supplier selection}

Several papers have studied the management of supply risks using supply risk indicators. For instance, Goa [3] developed an inventory management framework based on a Markov chain process for handling supply risks. Gao studied the timing of inventory hedging decisions, such as timely ramp-up of the safety stocks, based on the monitoring of suppliers' production and financial health. Gao et al. [9] investigated when and how to use supply risk indicators such as suppliers' production and financial health in managing a supply inventory over time. They showed that advance supply information has a large influence on mitigating the effect of supply disruptions on profits. Altug and Muharremoglu [10] proposed a simulation-based model, using supplier future capacity availability information, to determine an optimum inventory policy. They referred to supplier capacity information as 'advance supply information.' They investigated the value of sharing this information under different business scenarios and operating environment based on four parameters: utilization, capacity variability, demand variability, 
and the inventory level. They analysed the value of advance supply information under different scenarios. For instance, they showed that the advance supply information is most beneficial where the supplier capacity is variable. Atasoy et al. [11] applied supplier's stock information, production schedule, seasonality, preferences, and obligations as advance supply indicators to forecast supply disruption in an inventory management model. They showed that the benefits of advance supply information are not only in cost-saving but also in managing the system and increasing its robustness under uncertainty. Although advance supply information has been applied as a supply risk indicator for inventory management, they have been used more limitedly in the selection and order allocation process. Hu and Motwani [12] developed a supplier selection and order allocation model based on supply risk indicators. They focused on the effect of uncertainty in currency exchange rates and supplier capacity constraint and analysed order quantities and timing to suppliers to meet an expected profit. The dynamic relations between supply risk indicators and product cost and demand, and consequently the manufacturer's profit has been studied in a few papers. Guertler and Spinler [13] studied the relations between supply risk indicators and showed that monitoring the supply risk indicators is beneficial in disruption risk mitigation. They introduced and assessed 14 supply risk indicators that also informed the choice of supply risk indicators in this paper. Their focus was on analysing the importance of supply risk indicators as such, they did not consider supplier selection and order allocation in their study.

The review of the literature shows that for mitigating the risk of supply disruptions, it is imperative to rebalance a manufacturing supply portfolio considering suppliers' financial and production stability. This can be provided by using a decision-making framework, inputs to which are supply risk indicators offering early warning signals. Through continuous monitoring of supply risk indicators, any instability in suppliers' production or financial status can be detected before they cause a major supply disruption. Having interviewed experts from different industries, our paper identified a wide range of supply risk indicators influencing a manufacturer's profit. These indicators comprise financial stability (asset turnover, return on assets, equity to debt ratio, retained earnings to total asset ratio and working 
capital to total asset ratio), production stability (production technologies, capacity, facilities and quality control system), supply cost (supplier final price, currency exchange rate, production cost, tax policy, shipping cost) and supply quality. Some of these indicators are partially modelled in the literature.

Supplier selection and order allocation under uncertainty often face a trade-off between profit and risk. The more profit sought, the more risk must be undertaken; the best decision depends on the risk propensity of the decision maker. Several studies have explored the effect of the propensity for risk on mitigating supply chain risks [14-16]. They use measures such as variance [17], value at risk (VaR) [18], and conditional value at risk $(\mathrm{CVaR})[14,19,20]$ to set risk propensity. They modelled supplier selection from the viewpoint of the decision makers with different risk aversion levels. Merzifongluolu [14] proposed a supplier portfolio selection model for risk-neutral and risk-averse decision makers and concluded that the number of primary suppliers increases when the decision maker is more risk-averse. A highly risk-averse decision maker would increase reserve capacity instead of increasing the number of suppliers.

\subsection{Application of system dynamics and portfolio optimisation}

We applied a system dynamics technique to capture the dynamic relations in the supply chain. System dynamics is a system-based approach introduced by Forrester that simulates the cause and effect relations among system variables through mathematical equations [21]. System dynamic is applied widely in the literature to model the dynamic relations between supply chain elements [22-32]. Hsieh and Chou [33] developed a system dynamics model to simulate the effect of service innovation in small and medium-size enterprises to increase market competitiveness for those companies. Sudarto et al. [34] applied system dynamics to investigate the complex relations between system components and proposed a long-term capacity planning framework to achieve optimal sustainable performance. Rowzan [35] integrated system dynamics and a multi-objective optimisation to select a project portfolio.

To identify an optimal allocation of supply orders subject to risk propensity of a decision maker, we applied a portfolio optimisation. Portfolio optimisation is a technique which yields a set of optimal 
portfolios, that results in the highest expected profit for a defined level of risk. Portfolio optimisation was introduced by Markowitz in the case of financial portfolios [36] and has been widely applied for supplier portfolio selection in the literature. Exemplary works include [20, 37-40]. For instance, Sawik [39] proposed a portfolio approach combined with a mixed integer programming model for supplier selection under disruption risk to minimise expected costs and maximise expected performance. Sawik [20] in another article, applied the same combined approach to select suppliers to minimise the worst case supply costs. They analysed risk averse and risk-neutral suppliers in their risk management framework.

\subsection{Contribution of this study}

The novel aspect of this research stems from developing a multi-period supplier selection and order allocation optimisation framework over a planning horizon. The main pattern of behavior (archetype) in this model is the balance between supply risk and manufacturer's profit. Variations in supply cost and quality, supply delays, and financial and production instability affect a manufacturers' profit. A decision maker can control its exposure to those supply risks by determining a suitable supply portfolio over time.

This archetype, i.e. the balance of supply risk and profit, is developed by combining a system dynamics simulation model and a portfolio optimisation model. The portfolio optimisation model assists a decision maker to determine the efficient portfolio of suppliers given a certain level of profit risk: a portfolio of suppliers that maximises the expected profit at a certain level of risk acceptable by the decision maker. The efficient portfolio is therefore subject to the decision maker's propensity for risk.

The model also simulates how over time the decision makers' expectation of profit and related risk changes due to changes in supply material cost and quality. Decision maker's expectations over the financial and production stability of suppliers can also change. The decision makers' choice of efficient supply portfolio in the preceding periods also affects the status of the system. These dynamic relationships are simulated by a system dynamics model. 
To the best of our knowledge supplier selection and order allocation considering dynamic relations between supply risk indicators and manufacturer's profit is a novel framework not studied before in the literature. Particularly, the framework allocates supply orders based on decision makers' propensity for risk. It demonstrates the long-term impacts of risk aversion level of decision-makers on the manufacturer's profit and risk. The integration of the effect of risk propensity and supply risk indicators in an optimal order allocation framework is the second contribution of this paper.

The model developed enables managers to control a supply chain's risk and maximise a supply chain's value. The model can also be used for scenario plannining, where managers can use the model to develop plausible future scenarios and assess their actions in facing changes in furure periods. A manager can also asses how a change in their attitudes toward risk may affect their expected profits over a planning horizon.

This paper has expanded the model presented in [41] by developing a multi-period order allocation and supplier selection model. It has also expanded the system dynamics by amending financial risk indicators.

\section{Methodological approach}

\subsection{Problem definition}

A manufacturing supply chain is modelled, comprising I different suppliers, one manufacturer, and a manufacturing product market. Over a planning horizon of $n$ decision points, the manufacturer decides about the allocation of supply quantities to suppliers to increase their sales revenue and reduce the cost of product sold, i.e. to maximise profit. A set of indicators are defined to measure risks imposed by suppliers: changes in financial stability, production stability, quality, and cost indicators. To minimise the response time to these indicators, they are continuously monitored by the manufacturer.

As shown in Fig. 1, the inputs into the simulation model are (1) supply risk indicators, (2) relationships between risks, (3) manufacturer policies, including acceptable supply quality limit, acceptable probability of supply disruption, and inventory policy, and (4) manufacturing product market 
characteristic including demand growth, quality elasticity of demand, and price elasticity of demand. In practice, such data can be obtained from suppliers' annual reports, manufacturing databases, a survey of experts, and market research.

The simulation model yields the changes in suppliers' price, supply cost, and sales amount due to changes in supply indicators during the planning horizon. These outputs from the simulation, together with the manufacturing product market price, are then used as inputs into the portfolio optimisation model. The optimisation model yields the risk and returns for each allocation set and an efficient frontier on which every allocation set has the maximum profit for a specific level of risk. The optimal allocation set for the next period $(t+1)$ is determined based on the decision maker's level of risk aversion and it is an input to the subsequent simulation run i.e. for the next period $(t+2)$. This process is repeated until the end of the planning horizon. The simulation and the optimisation of the model are explained in detail in $\underline{\text { Sections } 3.3}$ and $\underline{3.4}$

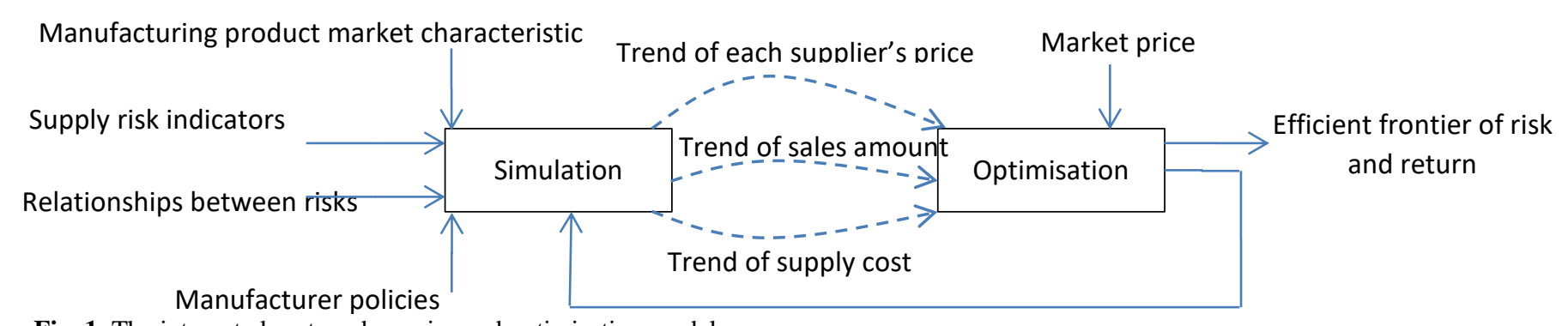

Fig. 1. The integrated system dynamics and optimisation model

\subsection{Model assumptions}

The main assumptions underpinning the model are as below:

- One unit of supply part is used in one unit of final product.

- At the beginning of the planning horizon, there are 100 units of supply available in inventory.

- The changes in manufacturing product cost and quality are only caused by the relative weighting of supplied materials and, therefore, the effect of other factors, such as manufacturing and retail cost variations, are excluded from the analysis. 
- Demand is elastic to product price and quality.

- The maximum amount of sales in the market for a period is calculated based on market demand, manufacturer production, and existing inventory within the period.

- The planning horizon is assumed to be three years.

- The initial order allocation is the current order allocation and is assumed to be $\left(S_{1}=0.1, S_{2}=\right.$ $\left.0.2, S_{3}=0.7\right)$.

- $\quad$ The acceptable product quality level, $Q_{s, t}$, is 0.02 .

- The acceptable supply disruption level, $P r_{s, t}$, is 0.05 .

- The minimum order weight from each supplier is 0.05 .

- The effect of suppliers' price on the supply cost is assumed to be nonspontaneous, due to the lags generated by product inventory.

\subsection{System dynamics simulation relations and equations}

In this simulation, the effect of suppliers' risk indicators on profit is modelled based on analysing the interrelations between these indicators and other supply chain parameters such as product sales amount and supply cost. To explain these interrelations, the model studies the supply chain in four interrelated sections including supply risk indicators, suppliers, manufacturers, customers, and the market as shown in Fig. 2. The equations for each element of the system are listed in Table $S$ in the Appendix A. 


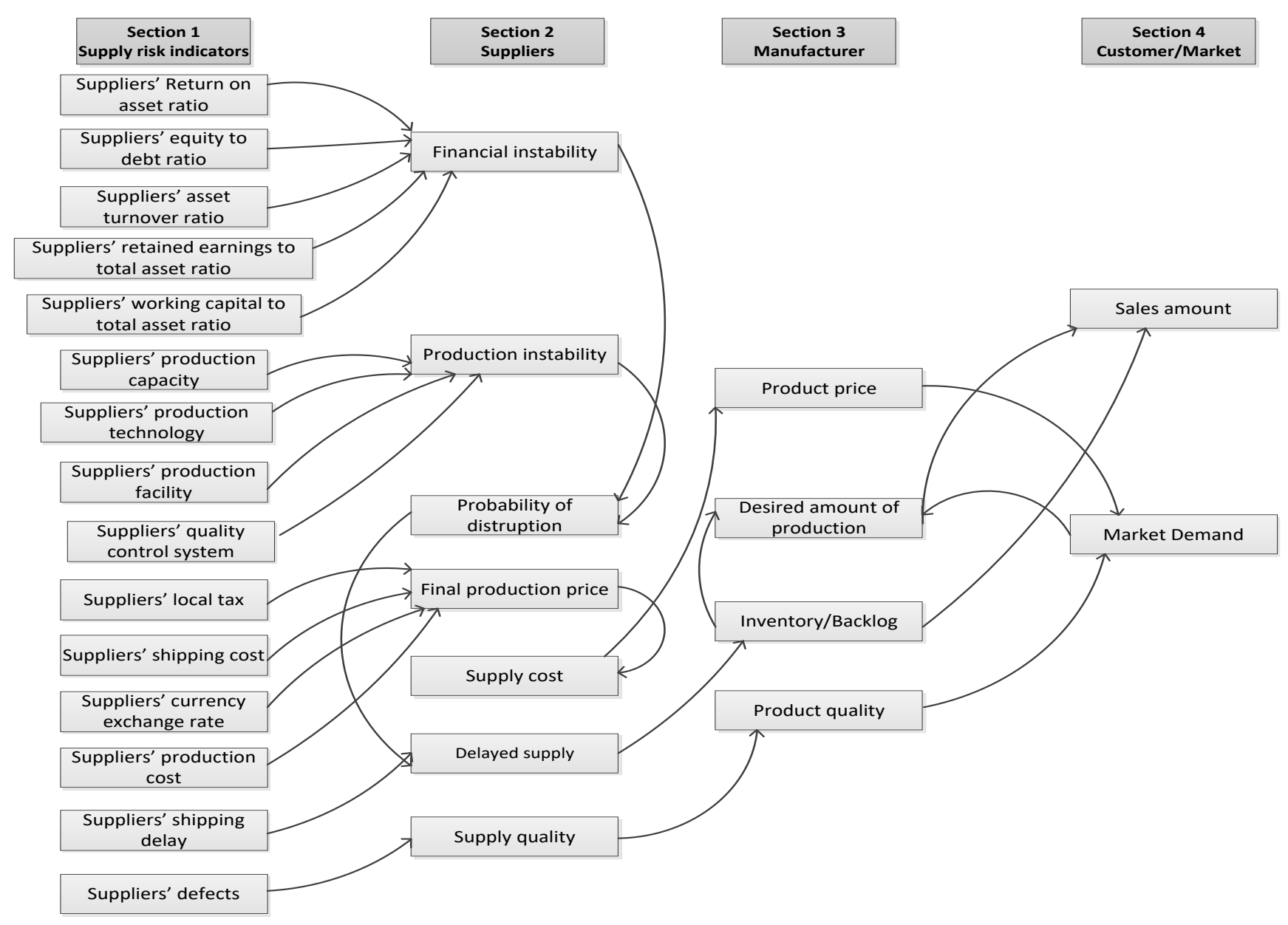

Fig. 2. The interrelations between system components modelled in this study

Section 1: Supply risk indicators

This study uses five financial indicators for each time period $t$ and supplier $S_{i}$ : (1) return on asset ratio, $R_{s_{i}, t}$, illustrates a supplier's profitability considering its total assets, (2) equity to debt ratio, $E_{s_{i}, t}$, shows the supplier's ratio of financing from investors to debt, (3) asset turnover ratio, $A_{s_{i}, t}$, indicates how efficiently a supplier can use its assets to generate sales, (4) retained earnings to total asset ratio, $R E_{s_{i}, t}$, indicates a supplier's reliance on debt, (5) working capital to total asset ratio, $W C_{s_{i}, t}$, measures a supplier's short-term assets to cover its short term liabilities. Suppliers' annual financial reports provide data for the calculation of these indicators. 
The production indicators in this study include production capacity, $P C_{s_{i}}$, production technology system, $P T_{s_{i}}$, production on facility, $P F_{s_{i}}$, and quality control system, $Q C_{s_{i}}$. The level and the weight of importance of these indicators can be determined through a survey of experts in the industry.

The factors affecting the supplier final product cost, $\widetilde{S}_{S_{i}, t}$, are supplier's local tax rate, $L T_{S_{i}}$, shipping cost, $S H_{s_{i}}$, currency exchange rate, $\widetilde{C R}_{S_{i}}$, and production cost, $\widetilde{F}_{S_{i}}$. It is assumed that $\widetilde{C R}_{S_{i}}$ and $\widetilde{F}_{S_{i}}$ are random variables with a normal distribution. This paper uses the operator ${ }^{\sim}$ to depict random variables. The data base related to $\widetilde{S}_{s_{i}, t}, \widetilde{C R}_{S_{i}}, S H_{S_{i}}, \widetilde{F}_{S_{i}}$ is assumed to be available. And $L T_{s_{i}}$ is rated for suppliers against each other by experts.

Supplier's shipping delay, $S H D_{S_{i}}$, is defined as the percentage of delayed shipping units per order. The supplier's defects, $Q_{s_{i}, t}$, is defined as the percentage of supply defects per order. In practice, $S H D_{s_{i}}$ and $Q_{s_{i}, t}$ can be extracted from manufacturing databases.

\section{Section 2: suppliers}

The sources of risk affecting the suppliers of the supply chain are identified in seven categories:

(1) Financial instability, $F D_{s_{i}}$, which is calculated based on Altman Z-score as shown in Eq.1.

$$
\text { Z-score }=1.2 W C_{s_{i}, t}+1.4 R E_{s_{i}, t}+3.3 R_{s_{i}, t}+0.6 E_{s_{i}, t}+1.0 A_{s_{i}, t}
$$

Altman Z-score has been commonly used to predict bankruptcy in companies [42]. It uses five key financial ratios, $W C_{s_{i}, t}, R E_{s_{i}, t}, R_{s_{i}, t}, E_{s_{i}, t}, A_{s_{i}, t}$, as explained in the previous section. A z-score less than 1.81 is an indication that the supplier is headed for bankruptcy. While a Z-score of 2.99 or above implies that the supplier is financially working well.

(2) Production instability, $P D_{s_{i}}$, which is calculated for each supplier based on supplier production criteria, $P C_{S_{i}}, Q C_{S_{i}}, P F_{S_{i}}, P T_{S_{i}}$. These criteria are determined by experts for each supplier.

(3) The probability of disruption, $\operatorname{Pr}_{s_{i}, t}$, due to bankruptcy or production inability which depends on $F D_{s_{i}}$ and $P D_{s_{i}}$. 
(4) Final production price, $\tilde{S}_{s_{i}, t}$, is affected by several risk indicators comprising, $L T_{S_{i}}, S H_{S_{i}}, \widetilde{C R_{S_{l}}}$, $\tilde{F}_{S_{i}}$

(5) Supply cost, $C_{t}$, which is determined by $\tilde{S}_{S_{i}, t}$.

(6) Delayed supply, $D_{s, t}$, indicates the amount of delayed orders which are not delivered to the manufacturer due to either supply disruption or shipping delay. It can be predicted based on $S H D_{s_{i}}$, and $\operatorname{Pr}_{s_{i}, t}$.

(7) Supply quality, $Q_{s, t}$, which is under the effect of $Q_{s_{i}, t}$. In fact, the supplier allocation set has a significant role on supply cost, delays, and quality. It indicates the contribution of each supplier on supply risks.

\section{Section 3: Manufacturer}

Supply risks affect several manufacturing factors such as (1) inventory, (2) production amount, (3) manufactured product quality, and (4) product price.

\section{Section 4: Customer/market}

In this model, the market demand is assumed to be elastic to product price and quality: demand for the product changes according to its price and quality. The price elasticity of demand $(\eta)$ and the quality elasticity of demand $(\gamma)$ are defined as the percentage change in quantity demanded due to a one percent change in price and quality, respectively, [43]. This model also assumes, the maximum amount of sales in the market for a period is calculated based on market demand, manufacturer production, and existing inventory within the period. The manufacturer can meet the market demand for the product if the sum of production and inventory is equal or more that the product demand, otherwise he would lose its market share.

the stock and flow diagram (SFD) in Fig. 3 depicts the effects of supply risk indicators on product demand and unit sales. The SFD shows the causal relationship between the system variables in the supply 
chain. It models a supply chain for a manufacturing company with a total number of $I$ suppliers $\left(S_{i}\right),(i \in$ $\{1, \ldots, I\})$. The important loops in the system dynamics model are explained in appendix B.

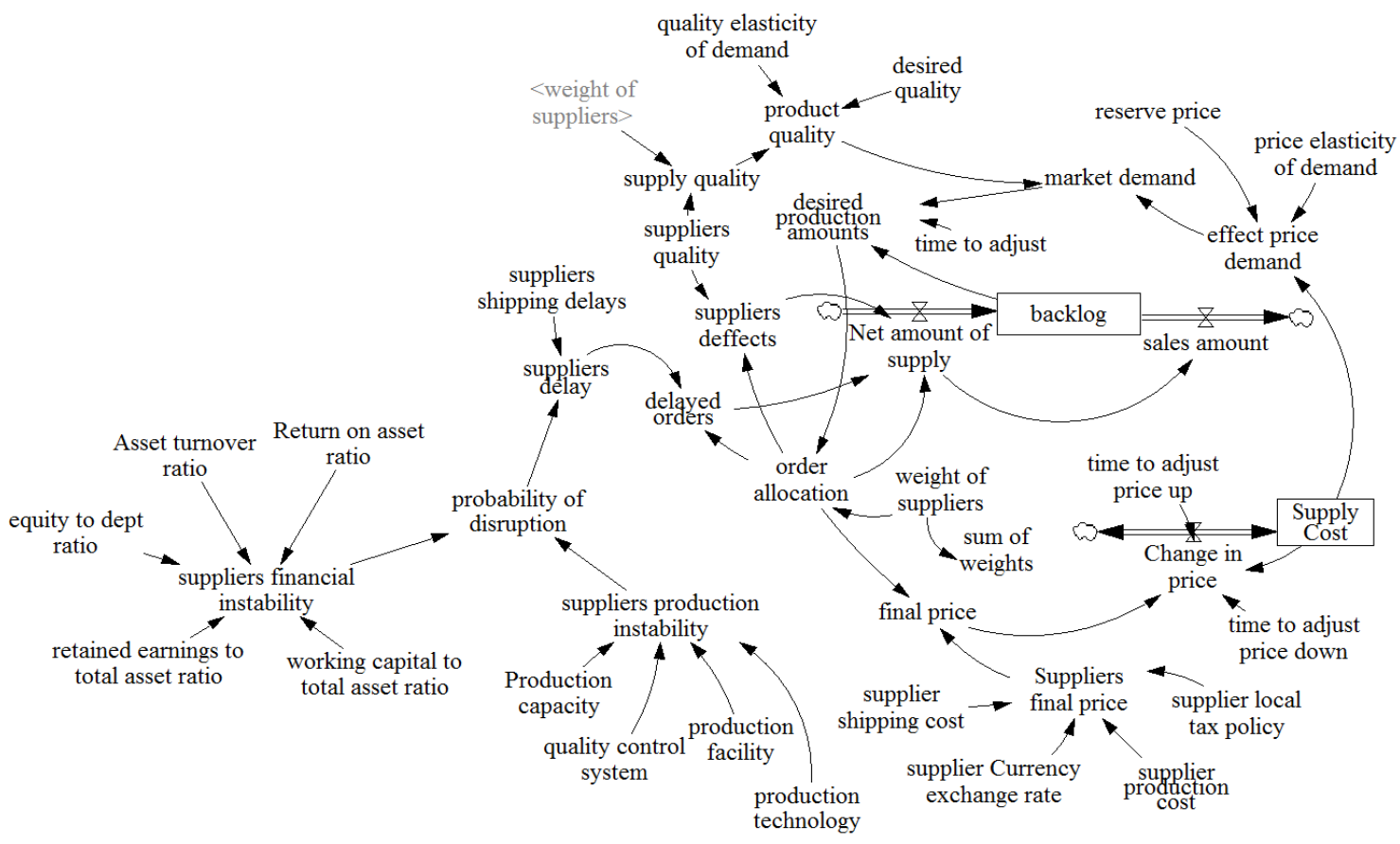

Fig. 3. The stock and flow diagram (SFD) of the simulation model

Manufacturer's profit in time $t,\left(\tilde{p}_{p_{t}}\right)$ is defined as the difference between operational revenue

$R_{t}=S M_{t} \cdot M_{p, t}$ and $\cos t C_{t}=C_{t_{o}}+\int_{t_{0}}^{t} \tilde{r}_{t} d t$, where $S M_{t}$ is the unit sales, and $M_{p, t}$ is the product market

price at time $t$. The product market price is assumed to be greater than supply cost by a fixed percentage.

Parameter $\tilde{r}_{t}$ is defined as the changes in the supply cost over a period $\left(t_{0}-t\right)$ and is calculated by Eq.

(2). As $\tilde{r}_{t}$ can be positive and negative, we used two ways flows to represent its chain on supply cost.

Parameter $C_{t_{0}}$ represents the initial supply cost at $t_{0}$.

$$
\tilde{r}_{t}= \begin{cases}\frac{\left(\tilde{S}_{s, t}-\tilde{S}_{s, t-1}\right)}{\tau_{d}}, & \tilde{S}_{s, t-1} \geq \tilde{S}_{s, t} \\ \frac{\left(\tilde{S}_{s, t}-\tilde{S}_{s, t-1}\right)}{\tau_{u}}, & \tilde{S}_{s, t-1}<\tilde{S}_{s, t}\end{cases}
$$

The effect of suppliers' price on the supply cost is assumed to be nonspontaneous, due to the lags generated by product inventory. The lag is introduced in the model based on a constant rate of change in 
price. Parameters $\tau_{u}$ and $\tau_{d}$ represent the duration of the times over which supply cost increases or decreases respectively in response to the changes in suppliers' price.

It is required to model the production inventory to track the accumulation of the manufactured product in the system over the planning horizon. This inventory of the product is called backlog in time $t$, $B_{t}$, and is estimated by $B_{t}=B_{t_{0}}+\int_{t_{0}}^{t}\left(N S_{t}-S M_{t}\right) d t$, where $B_{t_{0}}$ is the amount of backlog in time $t_{0}$. Backlog is assumed to be a stock variable. It is a stock of supply material that its amount increases with the receipt of supply orders and decreases with use in the manufacturing of the final product in proportion to sales amount. To maintain backlog at a specific amount it assumed that $N S_{t}=S M_{t}$. Note that when the amount of backlog is greater than zero, we use the term inventory; otherwise, a negative backlog is interpreted as unmet demand. Parameter $N S_{t}$ indicates the received amount of supply at time $t$ as calculated by $S_{t}=D P_{t}-Q_{s, t}-D_{s, t}$, where $D P_{t}$ represents the desired amount of production, which is assumed to be equal to the total amount of orders to suppliers (it is assumed that one unit of supply part is used in one unit of final product). Variable $Q_{s, t}$ indicates the number of supply defects and is calculated as $Q_{s, t}=\sum_{i}^{n} w_{i} . D P_{t} \cdot Q_{s_{i}, t} . D_{s, t}$ represents the amount of delayed orders which are not delivered to the

manufacturer by time $t$ and is calculated as $D_{s, t}=\sum_{i}^{n} w_{i} . D P_{t} \cdot\left(P r_{s_{i}, t}+S H D_{s_{i}}\right)$. Parameter $w_{i}$ represents the order weight for each supplier and is a number between zero and one. $D P_{t}$ is then estimated as the difference between product market demand, $D_{t}$, and backlog, $B_{t}$. The parameters and formula used in this simulation are listed in Table $\mathbf{S}$ in the appendices. Refer to Mokhtar et al.[41] for more detailed equations.

\subsection{Optimisation}

The results of the simulation are applied in an optimisation model to find the optimal allocation quantity for each supplier subject to a range of constraints. The concept of portfolio optimisation is applied to analyse the optimal order allocations to suppliers. Portfolio optimisation technique yields a set of optimal portfolio (in our case, supply order allocation) that offers the highest expected profit for a 
defined level of risk [44]. The result of portfolio optimisation is an efficient frontier. The efficient frontier is a line on which every allocation set has the maximum return for a specific level of a risk considering the constraints. The allocation sets under the efficient frontier have less return (profit) for a specific level of risk. Manufacturer's return $\left(\tilde{p}_{p}\right)$ as a result of order allocation set, $p$, is estimated as $\tilde{p}_{p}=\sum_{i=1}^{n} w_{i} \tilde{p}_{i}$, where $\tilde{p}_{i}$ is the manufacturer's return as a result of the allocation of the entire amount of supply to the supplier $i$. Note that $\tilde{p}_{i}$ is derived from the simulation. The expected manufacturer's return for supply allocation $\left(E\left[\tilde{p}_{p}\right]\right)$ is calculated by $E\left[\tilde{p}_{p}\right]=\sum_{i=1}^{n} E\left[w_{i} \tilde{p}_{i}\right]=\sum_{i=1}^{n} w_{i} \mu_{i}$, where $\mu_{i}$ represents the expected value for the distribution of a random variable $\tilde{p}_{i}$.

In this research, the standard deviation has been implemented as the risk measure for return, $\tilde{p}_{p}$, this can be written as,

$$
\sigma\left[\tilde{p}_{p}\right]=\sqrt{\sigma^{2}\left[\tilde{p}_{p}\right]}=\sqrt{\sum_{i=1}^{n} w^{2}{ }_{i} \sigma^{2}\left[\tilde{p}_{p}\right]+\sum_{i=1}^{n} \sum_{j=i+1}^{n} 2 w_{i} w_{j} \operatorname{cov}\left[\tilde{p}_{i}, \tilde{p}_{j}\right]}
$$

The optimisation problem can be formulated as follows:

$\operatorname{Max} E\left[\tilde{p}_{p}\right]$

Subject to:

$$
\begin{aligned}
& \sigma\left[\tilde{p}_{p}\right]-\sigma_{t} \leq 0 \\
& \sum_{i=1}^{I} w_{i} * Q_{s_{i}, t} \leq A Q_{s, t} \\
& \sum_{i=1}^{I} w_{i} * P r_{s_{i}, t} \leq P r_{s, t} \\
& \sum_{i=1}^{I} w_{i}=1 \\
& 0.05 \leq w_{i} \leq 1
\end{aligned}
$$

where $\sigma_{t}$ in Eq. (5) is the decision maker's acceptable level of standard deviation of portfolio return. Parameter $A Q_{s, t}$ in Eq. (6) indicates the acceptable level of supply quality, e.g. $A Q_{s, t}=0.02$ illustrates 2 defectsamong 100 units of supply. In Eq. (7) $P r_{s, t}$ specifies the acceptable level of supply 
disruption probability. This variable depends on manufacturer propensity for supply disruption risk. Eq. (9) shows that the minimum order to each supplier is limited to 5 per cent to avoid isolating a supplier who manufacturer may need at a later date.

The optimal weights of suppliers for period $t+1$ will be derived from the optimisation, then the simulation will be repeated for the next period based on optimal weights obtained from optimisation and the latest supply risk indicators to investigate the trend of sales amount and supply cost for period $t+2$, the result of the second simulation will apply to discover the supplier order allocation for that period. In this framework, the model has been run for three periods and it shows how much should be ordered from each supplier to maximise the manufacturer's profit.

\section{Numerical example and discussion}

\subsection{Materials and methods}

This paper develops a case study based on our knowledge of supplier selection gained through interview sessions with experts from pharmaceutical and electricals manufacturing supply chains. We found that many of the data we required for the model was not available. Many of this data was not available because those companies did not consider that data in their procurement decisions. This data, for example, included production stability and financial stability of suppliers. However, industry experts agreed with us that this sort of data can enhance their procurement decision and is relevant to supply decision making. We collected information to the extent that the application of the model developed can be illustrated via examples. We therefore sought experts' views on setting reasonable values for the input parameters to the model.

Where applicable, the equations introduced in Section 3 are calibrated by data and information received from experts. Experts rated production instability indicators and tax policy for each of the three suppliers against each other, as shown in Table 1. For the suppliers used in the case study financial parameters are gathered from annual reports available online. Cost indicators are either extracted from available databases or estimated by experts. For instance, currency exchange rates are extracted from the 
PACIFIC exchange rate service [45] provided by the University of British Colombia. A normal distribution was fitted to the exchange rate and production cost using the Maximum Likelihood Method. Average and standard deviation of the distributions are shown in Table 1. For instance, the distribution fitting process for the currency exchange rate is shown in Fig. 4. Initial values of the variables at the beginning of the planning horizon are set arbitrary and in consultation with experts. They are varied in several scenarios to analyse the sensitivity of the outcomes of the model to those values.
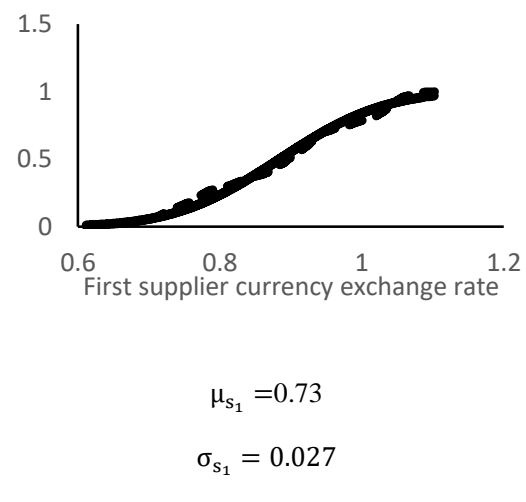

p-value $>0.05$

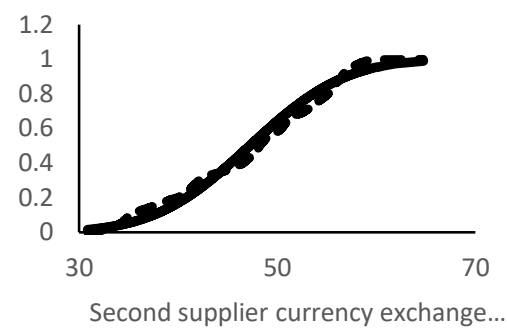

$\mu_{\mathrm{s}_{2}}=49.25$

$\sigma_{\mathrm{s}_{2}}=1.52$

p-value $>0.05$

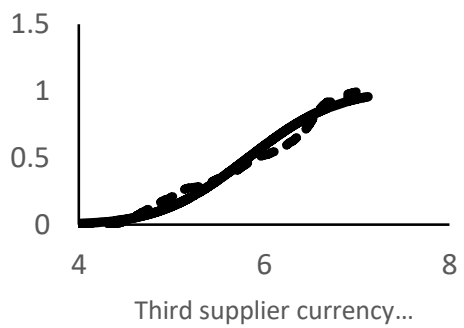

$\mu_{\mathrm{s}_{3}}=4.8$

$\sigma_{\mathrm{s}_{3}}=0.15$

p-value $>0.05$

- - Cumulative distribution function of data

Normal distribution

Fig. 4. distribution fitting for currency exchange rate data

The model is implemented in Vensim, Matlab, and Microsoft Excel. Vensim is applied to model the system dynamics simulation and Matlab is applied for modelling the portfolio optimisation. Microsoft Excel is applied for statistical analysis and distribution fitting.

\subsection{Simulation results}

To show the application of the model, a numerical example is presented based on a hypothetical manufacturing process for a specific product. The manufacturer has three suppliers $S_{1}, S_{2}$, and $S_{3}$ from

countries A, B, and C, respectively. It is assumed that data related to $S H D_{\mathrm{s}_{\mathrm{i}}}, \widetilde{\mathrm{F}}_{\mathrm{S}_{\mathrm{i}}}, \widetilde{\mathrm{CR}}_{\mathrm{s}_{\mathrm{i}}}, \mathrm{Q}_{\mathrm{s}_{\mathrm{i}}, \mathrm{t}}$, and $\mathrm{LT}_{\mathrm{s}_{\mathrm{i}}}$ are available for the past 36 months of the transaction with suppliers. The length of the planning horizon is $\mathrm{T}=3$ years, with a monthly discretization level. It is also assumed that the required financial ratios are available through annual financial reports published by the suppliers. At the beginning of the planning 
horizon (i.e. $\mathrm{t}=0$ ), the simulation is run with initial supplier weights; however, for the succeeding periods, the system dynamics model is run with the suppliers' weights derived from the optimisation step. This model has been run for three periods, each period containing 12 months. The parameters for the simulation runs of the three periods are shown in Table 1. 
Table 1

Parameters used in the simulation of the manufacturing process

\begin{tabular}{|c|c|c|c|c|c|c|c|c|c|c|c|c|c|c|c|c|c|c|}
\hline \multirow{3}{*}{$\begin{array}{l}\text { Parameters } \\
\text { Random variables }\end{array}$} & \multicolumn{6}{|c|}{$T_{1}$} & \multicolumn{6}{|c|}{$T_{2}$} & \multicolumn{6}{|c|}{$T_{3}$} \\
\hline & \multicolumn{2}{|c|}{$\mathrm{S}_{1}$} & \multicolumn{2}{|c|}{$\mathrm{S}_{2}$} & \multicolumn{2}{|c|}{$\mathrm{S}_{3}$} & \multicolumn{2}{|r|}{$S_{1}$} & \multicolumn{2}{|c|}{$\mathrm{S}_{2}$} & \multicolumn{2}{|c|}{$\mathrm{S}_{3}$} & \multicolumn{2}{|c|}{$\mathrm{S}_{1}$} & \multicolumn{2}{|c|}{$\mathrm{S}_{2}$} & \multicolumn{2}{|c|}{$\mathrm{S}_{3}$} \\
\hline & Mean & Stdev. & Mean & Stdev. & Mean & Stdev. & Mean & Stdev. & Mean & Stdev. & Mean & Stdev. & Mean & Stdev. & Mean & Stdev. & Mean & Stdev. \\
\hline $\begin{array}{l}\tilde{F}_{S_{i}}(\text { supplier's local } \\
\text { currency/unit) }\end{array}$ & 87 & 1.5 & 5840 & 140 & 541 & 15 & 88 & 3 & 5800 & 340 & 540 & 35 & 80 & 3 & 5270 & 250 & 530 & 30 \\
\hline $\begin{array}{l}\widetilde{C R}_{S_{i}} \text { (supplier's } \\
\text { local currency } \\
\text { /manufacturer's } \\
\text { currency) }\end{array}$ & 0.73 & 0.027 & 49.25 & 1.52 & 4.8 & 0.15 & 0.75 & 0.015 & 50 & 0.95 & 5 & 0.13 & 0.75 & 0.014 & 50.5 & 0.66 & 5.1 & 0.06 \\
\hline Constant variables & \multicolumn{2}{|c|}{$\mathrm{S}_{1}$} & \multicolumn{2}{|c|}{$\mathrm{S}_{2}$} & \multicolumn{2}{|c|}{$\mathrm{S}_{3}$} & \multicolumn{2}{|c|}{$\mathrm{S}_{1}$} & \multicolumn{2}{|c|}{$\mathrm{S}_{2}$} & \multicolumn{2}{|c|}{$\mathrm{S}_{3}$} & \multicolumn{2}{|c|}{$\mathrm{S}_{1}$} & \multicolumn{2}{|c|}{$\mathrm{S}_{2}$} & \multicolumn{2}{|c|}{$\mathrm{S}_{3}$} \\
\hline$S H D_{s_{i}}$ & \multicolumn{2}{|c|}{0.01} & \multicolumn{2}{|c|}{0.02} & \multicolumn{2}{|c|}{0.04} & \multicolumn{2}{|c|}{0.01} & \multicolumn{2}{|c|}{0.01} & \multicolumn{2}{|c|}{0.05} & \multicolumn{2}{|c|}{0.01} & \multicolumn{2}{|c|}{0.02} & 0.06 & \\
\hline$R_{s_{i}, t}$ & & .42 & & 35 & & .32 & & .43 & & .42 & & .4 & & 44 & & .42 & 0.43 & \\
\hline$A_{s_{i}, t}$ & & .84 & & .79 & & 1.7 & & 2.3 & & 2.2 & & .3 & & 2 & & 2 & 2 & \\
\hline$E_{s_{i}, t}$ & & 3 & & .5 & & 2.2 & & 3.4 & & 3.4 & & .4 & & 4 & & 4 & 4 & \\
\hline$R E_{s_{i}, t}$ & & .75 & & .7 & & 65 & & 0.8 & & 0.8 & & .8 & & .9 & & 0.8 & 0.8 & \\
\hline$W C_{s_{i}, t}$ & & .18 & & 12 & & .11 & & 0.2 & & 0.2 & & .2 & & 35 & & 0.3 & 0.3 & \\
\hline$P C_{s_{i}}$ & & 0.9 & & .8 & & 0.8 & & 0.9 & & 0.8 & & .8 & & .9 & & 0.8 & 0.8 & \\
\hline$Q C_{s_{i}}$ & & 0.8 & & .7 & & 0.6 & & 0.8 & & 0.7 & & .6 & & .8 & & .7 & 0.6 & \\
\hline$P F_{s_{i}}$ & & 0.9 & & .8 & & 0.7 & & 0.9 & & 0.8 & & .7 & & .9 & & 0.8 & 0.7 & \\
\hline$P T_{s_{i}}$ & & 0.9 & & .8 & & 0.5 & & 0.9 & & 0.8 & & .5 & & .9 & & 0.8 & 0.5 & \\
\hline$L T_{s_{i}}$ & & .03 & & .02 & & .01 & & .04 & & .02 & & .01 & & .06 & & .02 & 0.008 & \\
\hline
\end{tabular}


$\mathrm{SH}_{s_{i}}$ (manufacturer currency/unit)

$\mathrm{Q}_{\mathrm{s}_{\mathrm{i}}, \mathrm{t}}$
5

0.01
4.5

0.03
5.5

0.017

0.019
4.5

0.021

7

5.5

0.0

0.018

0.022 
Results of system dynamics simulation are shown in Fig. 5. Panel (a) depicts the trends of sales amount $\left(S M_{t}\right)$ and supply cost $\left(C_{t}\right)$ over the period $T=1$. The variation in sales amount is due to given weights and the fluctuation of supply risk indicators. Panel (b) depicts the variation of suppliers' final price $\left(\tilde{S}_{S_{i}, t}\right)$ which is determined by the fluctuation of $S H D_{S_{i}}, \widetilde{F}_{S_{i}}, \widetilde{C R}_{S_{i}}$. These simulation results are used as input into the optimisation stage as explained in

\section{Section 4.2.}

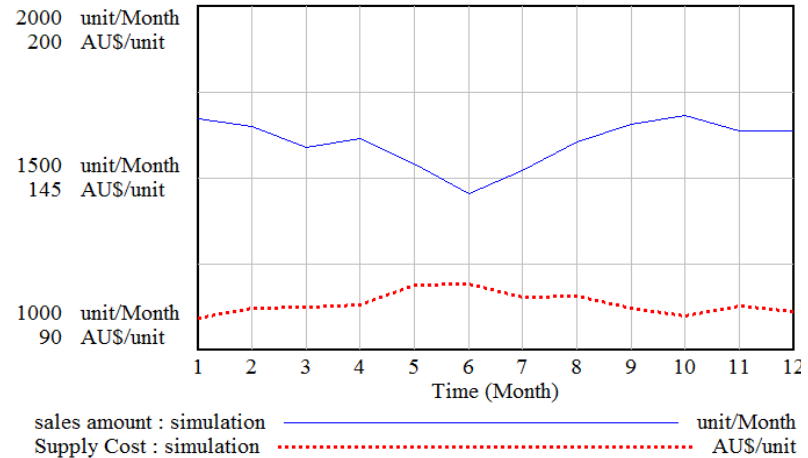

Panel (a)

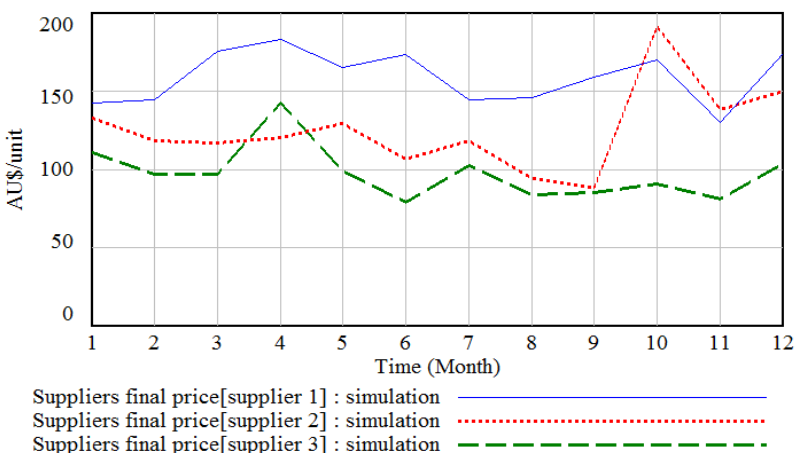

Panel (b)

Fig. 5. The results of the simulation model for the first period, Panel (a): The trend of $S M_{t}$ and $C_{t}$. Panel (b): The $\tilde{S}_{s_{i}, t}$.

\subsection{Optimisation results}

Results of optimisation, for all three periods of the planning horizon, are shown in Fig. 6. Any point on the profit-risk scale in the graph represents a supplier allocation set. One thousand supplier order allocation set is randomly generated to show how the optimisation model identifies those allocation sets with the highest level of return at specified levels of risk, i.e. the efficient frontier, subject to constraints. The solid lines in Panels (a) to (f) represent the efficient frontier. The allocation sets under the efficient frontier have less return (profit) for a specific level of risk and the allocation sets above the efficient frontier do not satisfy the optimisation constraints.

Fig. 6 also shows the risk and return for the allocation set where the whole orders are allocated to only one of the suppliers (shown by points $S_{1}, S_{2}$, and $S_{3}$ on graphs). It is to be noted how distributing 
orders among suppliers can yield an enhanced allocation set in terms of risk and return. For instance, looking at the result of optimisation in Panel (a) should the manufacturer, at $T=1$, allocate all orders to the supplier $S_{1}$, the expected return is zero with a risk of 0.09 . The result of optimisation shows that the manufacturer has to choose the supply allocation set A as annotated on the efficient frontier. For the same level of risk (0.09), the manufacturer expects a higher expected return of the order 0.13 when the order is almost evenly distributed $\left(w_{1}=0.27, w_{2}=0.37, w_{3}=0.36\right)$ among all three suppliers.

It should be noted that the efficient frontier provides a range of optimal allocation sets with different levels of risk and return. The ultimate decision to choose from the points on the efficient frontier depends on the decision maker's propensity for risk. To account for the different propensity for risk, two decision-making scenarios are investigated: (1) High level (H.L.) of risk-aversion, and (2) Low level (L.L.) of risk-aversion. It is assumed that a decision maker with a high level of risk-aversion chooses the lowest feasible risk (and return) on the efficient frontier (for instance, see point B on panel (a)), and a decision maker with a low level of risk-aversion chooses the highest feasible level of risk on the efficient frontier (e.g. see point $\mathrm{C}$ on panel (a)). The allocation set results for period $T=1$ for both H.L. and L.L. of risk aversion scenarios are shown in Fig. 7. The decision maker with a high level of risk aversion allocates the majority of their order to the supplier $S_{1}\left(w_{1}=0.6\right)$. Note that supplier $S_{1}$ is the supplier with the lowest level of risk among all suppliers. The small amount of allocation $\left(w_{3}=0.05\right)$ to supplier $S_{3}$ is due to the minimum order constraint defined in the optimisation model. Results for the low level of risk aversion show that the order is almost halved between suppliers $S_{2}$ and $S_{3}$.

It is assumed that the manufacturer constantly monitors the status of suppliers in terms of supply risk indicators. For the next period $T=2$, the manufacturer feeds the system dynamics model with updated supply risk indicators (as shown in Table 1) and the optimal allocation weights from the previous step of optimisation. The output of the system dynamics model yields sales amount and supply costs for the next run of optimisation model to derive optimal allocation sets for period $T=2$. 
Results of optimisation for this period are shown in Fig. 6, panel (c). An inspection of results shows that a decision maker with a high level of risk aversion allocates a lion's share of the order to the supplier $S_{1}$. Small allocation of $w=0.05$ to suppliers $S_{2}$ and $S_{3}$ is set to meet the minimum allocation constraint. This finding is consistent with the risk amounts estimated for full allocations to each supplier. As shown in Table 2, the full order allocation to supplier $S_{1}$ yields the lowest level of risk (0.03). A decision maker with a low level of risk aversion allocates the order to suppliers $S_{2}$ and $S_{3}\left(w_{2}=\right.$ $0.40, w_{3}=0.55$ ) (Fig. 6, panel (d)). As shown in Table 2, suppliers $S_{2}$ and $S_{3}$ lead to a significantly higher return for the manufacturer when compared to supplier $S_{1}$.

Fig. 6, panel (e), depicts the result of optimisation from the view of a decision maker with a high level of risk aversion for the third period $(T=3)$. The efficient frontier is annotated to show that the minimum risk allocation set which meet the constraints is distributing the orders among supplier as $\left(w_{1}=\right.$ $\left.0.45, w_{2}=0.32, w_{3}=0.23\right)$. This allocation set yields the lowest risk (0.056); however, still, the higher amount of orders is allocated to the supplier $S_{1}$ with the less level of risk. Panel (f) illustrates that the higher return allocation set in L.L risk aversion scenario is achieved through allocating the orders to suppliers $S_{2}$ and $S_{3}$ with considerable higher returns for manufacturer $\left(w_{2}=0.35, w_{3}=0.60\right)$.

H.L. Risk-aversion

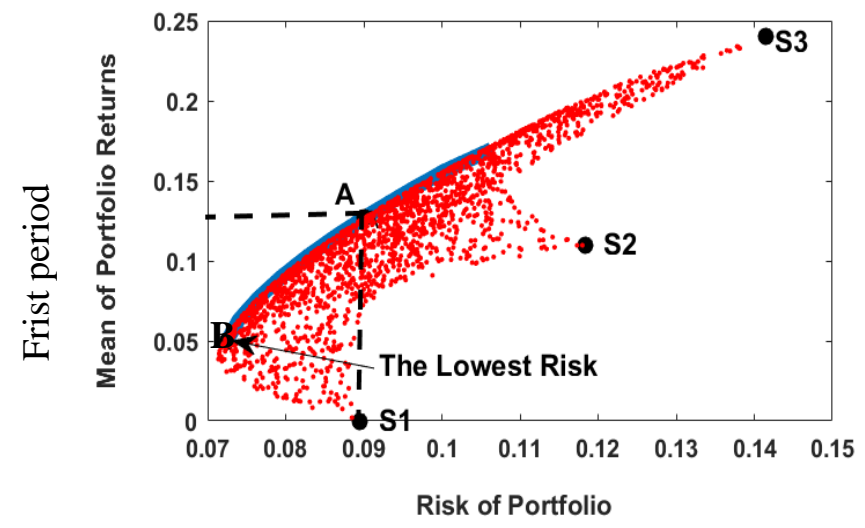

Panel (a)

\section{L.L. Risk-aversion}

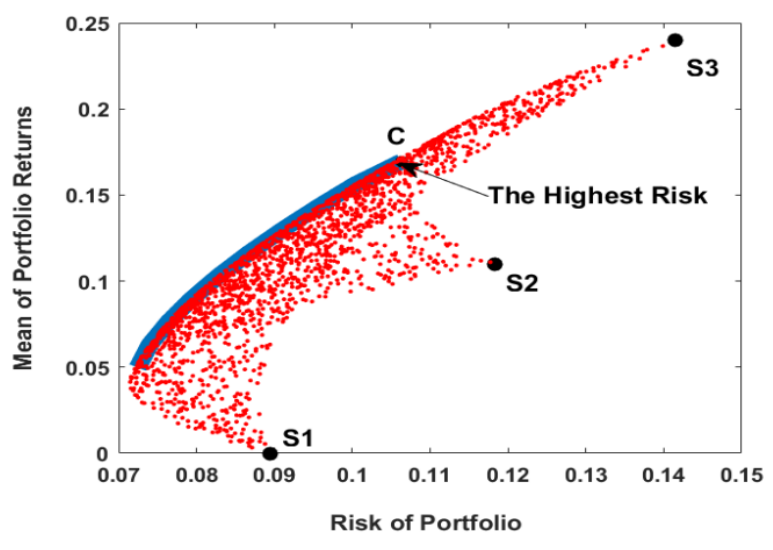

Panel (b) 


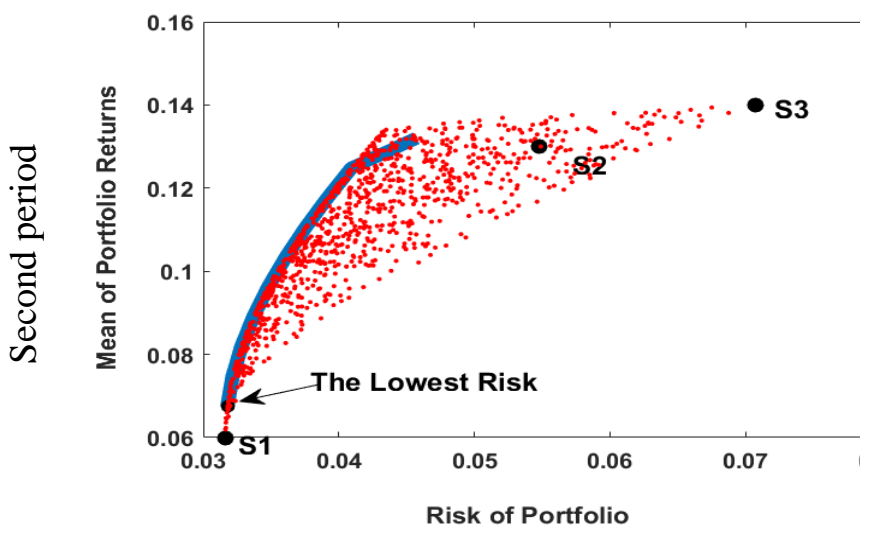

Panel (c)

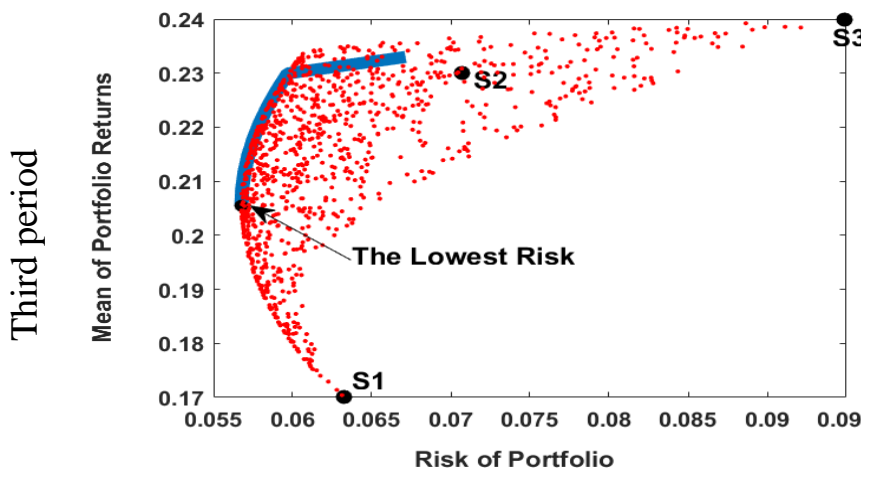

Panel (e)

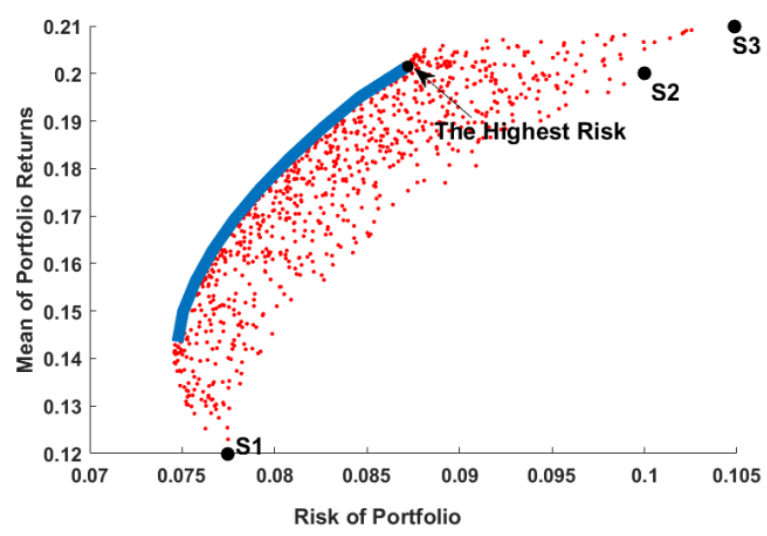

Panel (d)

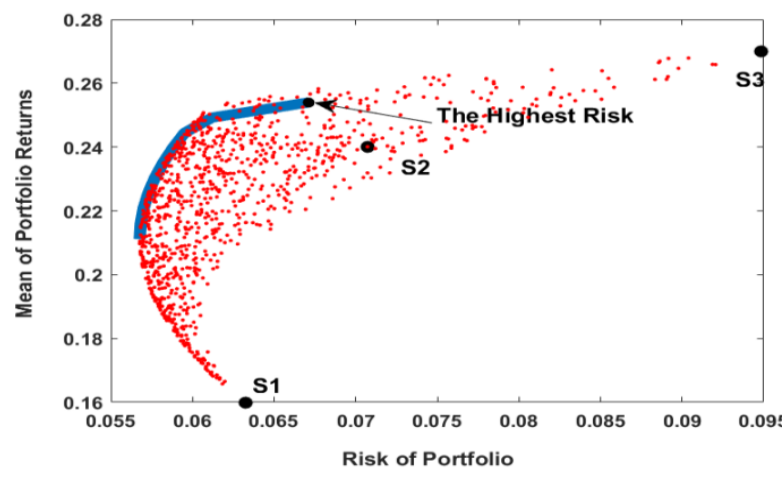

Panel (f)

Fig. 6. Efficient frontier and random supplier order allocation for H.L. risk averse (left panels) and L.L. risk averse (right panels) decision makers for three periods.

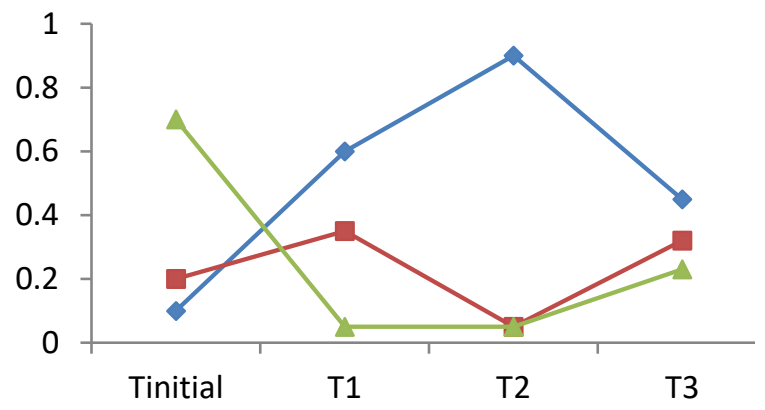

—Supplier 1

Panel (a)

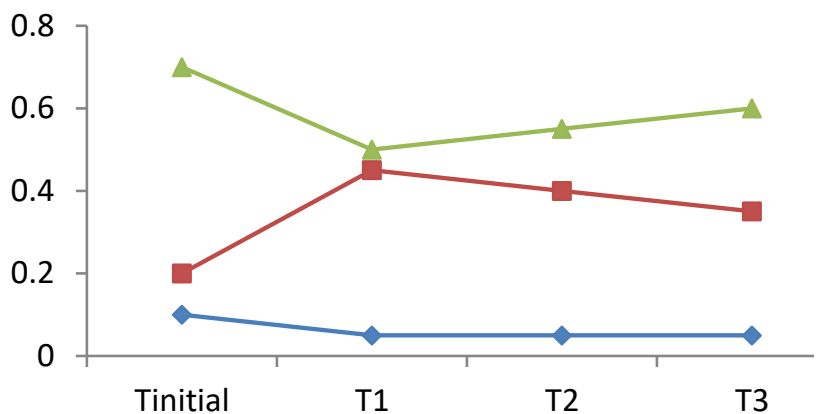

Supplier 2

Panel (b)

Fig. 7. Supplier order allocation for three periods, Panel (a): when the decision maker is High Level (H.L) risk-averse. Panel (b): when the decision maker is Low Level (L.L) risk-averse

Table 2

The applied data in the optimisation

H.L. Risk-aversion

\begin{tabular}{cccccccccc}
\hline & $T_{1}$ & & $T_{2}$ & & & $T_{3}$ & \\
\hline$S_{1}$ & $S_{2}$ & $S_{3}$ & $S_{1}$ & $S_{2}$ & $S_{3}$ & $S_{1}$ & $S_{2}$ & $S_{3}$
\end{tabular}




\begin{tabular}{clllllllll}
$\tilde{p}_{i}$ & 0.001 & 0.11 & 0.24 & 0.06 & 0.13 & 0.14 & 0.17 & 0.23 & 0.24 \\
$\sigma\left[\tilde{p}_{i}\right]$ & 0.02 & 0.03 & 0.07 & 0.04 & 0.05 & 0.07 & 0.08 & 0.09 & 0.095 \\
$P r_{S_{i}, t}$ & 0.02 & 0.03 & 0.07 & 0.02 & 0.025 & 0.03 & 0.02 & 0.025 & 0.03 \\
$\mathrm{Q}_{\mathrm{s}_{\mathrm{i}}, \mathrm{t}}$ & 0.01 & 0.01 & 0.03 & 0.017 & 0.019 & 0.021 & 0.01 & 0.018 & 0.022 \\
order allocation & 0.6 & 0.35 & 0.05 & 0.90 & 0.05 & 0.05 & 0.45 & 0.32 & 0.23 \\
L.L. Risk-aversion & & & & & & & & & \\
\hline & & $T_{1}$ & & & $T_{2}$ & & & $T_{3}$ & \\
\hline$\tilde{p}_{i}$ & $S_{1}$ & $S_{2}$ & $S_{3}$ & $S_{1}$ & $S_{2}$ & $S_{3}$ & $S_{1}$ & $S_{2}$ & $S_{3}$ \\
$\sigma\left[\tilde{p}_{i}\right]$ & 0.001 & 0.11 & 0.24 & 0.12 & 0.20 & 0.21 & 0.16 & 0.24 & 0.27 \\
$P r_{s_{i}, t}$ & 0.02 & 0.03 & 0.07 & 0.07 & 0.1 & 0.1 & 0.06 & 0.07 & 0.09 \\
$\mathrm{Q}_{\mathrm{s}_{\mathrm{j}}, \mathrm{t}}$ & 0.02 & 0.03 & 0.07 & 0.02 & 0.025 & 0.03 & 0.02 & 0.025 & 0.03 \\
order allocation & 0.01 & 0.01 & 0.03 & 0.017 & 0.019 & 0.021 & 0.01 & 0.018 & 0.022 \\
& 0.05 & 0.45 & 0.50 & 0.05 & 0.40 & 0.55 & 0.05 & 0.35 & 0.60
\end{tabular}

The optimal allocation of orders at each period yields an expected return and risk for the manufacturer. Fig. 7 depicts those return and risks based on the risk propensity scenarios. As shown in panel (b), generally the level of expected return for a decision maker with a lower level of risk aversion is higher than that for a decision maker with a higher level of risk aversion. A more expected return entails more risk, and hence as presented in panel (a), the level of risk for a decision maker with a low level of risk aversion is higher than that for a decision maker with a high level of risk aversion. The contribution of the developed model for the management of risk can be further explained by the general trend of risk and return during the planning horizon. As Fig. 8 shows over the planning horizon manufacturers return increases as the risk of return decreases. To put it in other words, using the risk management framework presented, the manufacturer constantly monitors the status of suppliers by tracing the supply risk indicators and distributes orders to optimise their risk and return on profit. Over the course of the planning horizon, this optimal allocation of orders is expected to yield a higher return on profit and a lower level of risk.

This model is used to make optimal decisions under uncertainty. The decisions identified as optimal are based on the expectations of the future. These expectations may not be realized as expected when a future period comes. In hindsight, the decision maker may realize that a decision identified as optimal, was not optimal. 

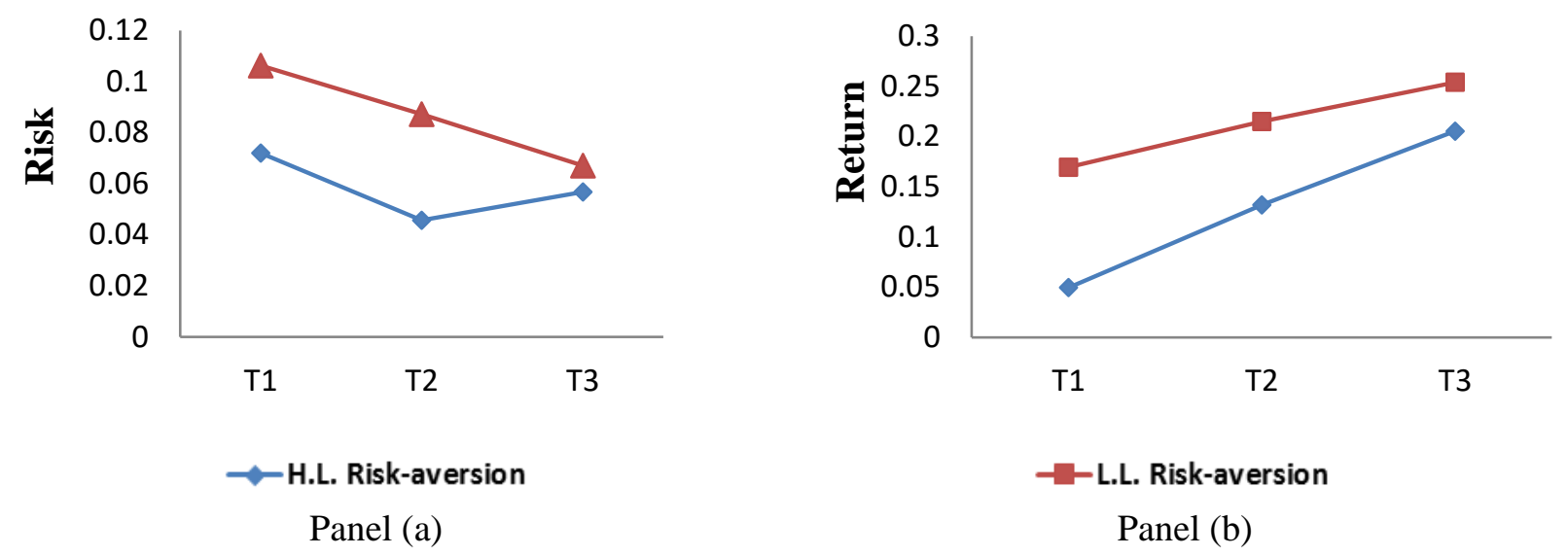

Fig. 8. risk and return for three periods for H.L risk-averse and L.L risk-averse decision maker, Panel (a): Risk, Panel (b): Return

\section{Validation of model}

The validity of a model indicates the suitability of the model in serving its purpose. Validation of a system dynamics model is complex due to the reason that judging the validity of philosophical and technical aspects of the model is complicated [46]. Based on [46], the validity of the system dynamics model mainly means the validity of its internal structure and it cannot be assessed only quantitatively. To build confidence that the model is working appropriately, we conducted qualitative tests such as expert reviews, inspection, and walkthroughs. The quantitative tests to check the validity of a system dynamics model includes dimensional constancy, sensitivity analysis, extreme conditions, and behaviour reproduction $[21,46]$ as explained below. The validation of the model is conducted by all the mentioned tests except behaviour reproduction. First, a behaviour reproduction requires assumptions about decision makers' propensity for risk, which itself can vary over time. We did not have access to any data to measure decision makers' propensity for risk. Second, the model developed provides outcomes based on the expectation of several stochastic variables in the future. It is possible that the outcomes of the model simply diverge from observed data due to the probabilistic nature of system variables. A repeated comparison of observed data and model outcomes over many periods can provide an indication of the 
validity of the model. Such validation method warrants the adoption of the method by a decision maker to observe the effects of using the model on risk and profits for a manufacturer.

\subsection{Dimensional consistency}

Each equation in our model is tested in terms of dimensional consistency via the Vensim automated dimensional analysis, and with walk-through of the model. The response of the each equation is tested for different inputs to make sure that they are working logically. The feasibility of each equation is examined against maximum and minimum amounts of inputs.

\subsection{Sensitivity analysis}

A sensitivity analysis is conducted for two key parameters of the system, supply cost and sales amount. We analysed these two parameters against order allocated to each supplier. For this purpose, we run the model for the three scenarios in which the whole orders are allocated to one supplier -if other parameters are the same as Table $1, T_{3^{-}}$and observe the supply cost and sales amount behaviour as shown in Fig. 9. The sensitivity analysis shows that allocating entire orders to the third supplier results in less supply cost and higher sales amount; while, allocating the whole orders to the first supplier leads to more supply cost, and therefore less sales amount. This result shows that the higher supply cost leads to lower sales amount which is an expected result.

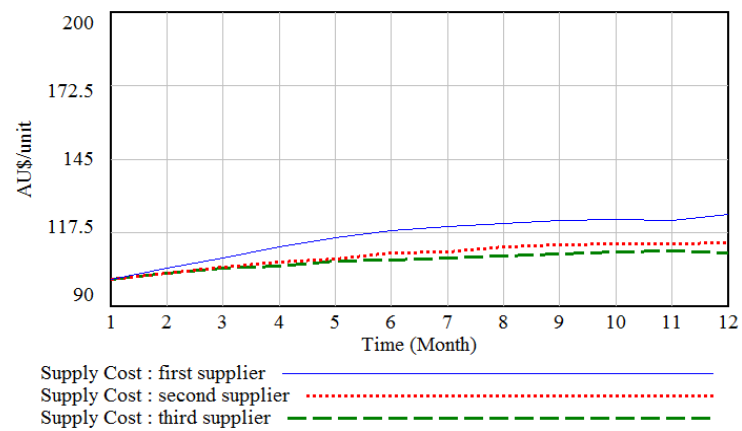

Panel(a)

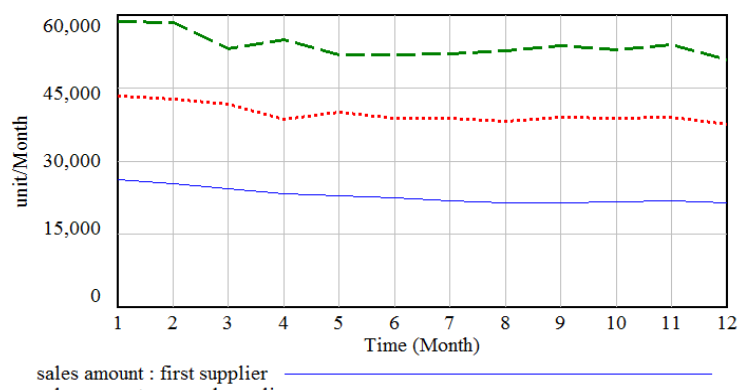

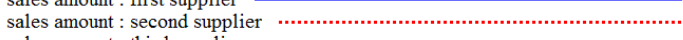
sales amount : third supplier

Panel(b)

Fig 9. Supply cost (Panel(a)), and sales amount (Panel(b)) when entire orders allocated to one supplier 


\subsection{Extreme conditions test}

Models should behave logically in extreme conditions, meaning that the result of the model should be robust against extreme inputs[21]. For instance, the sales amount should fall to zero when the supply price rises high enough. To conduct this test for our model we assumed that the suppliers' price increases by 10 times and analysed the sales amount and supply cost. The results of the model passed the extreme conditions test by showing that the amount of sales is falling to zero when the supply cost is increasing. Results are shown in Fig. 10.

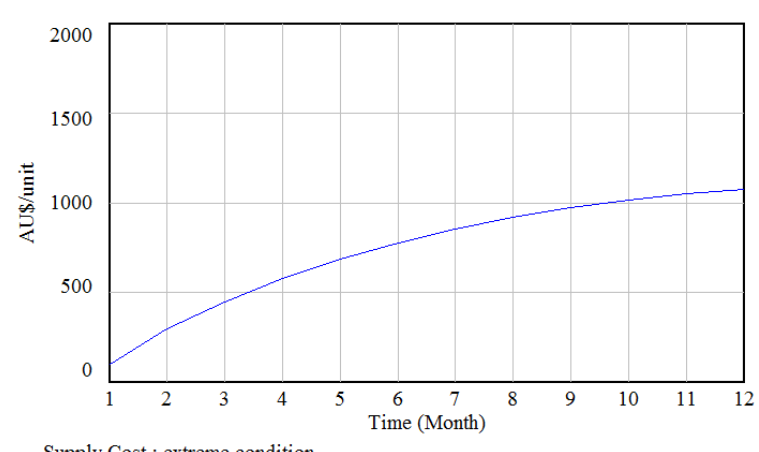

Supply Cost : extreme condition

Panel(a)

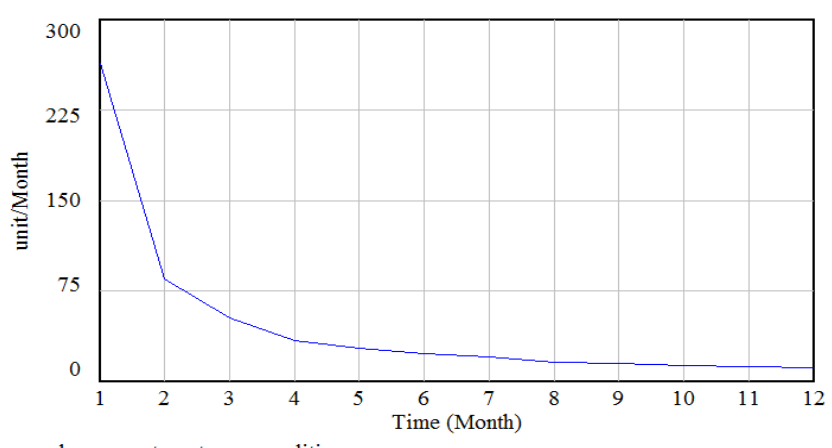

sales amount : extreme condition

Panel(b)

Fig 10. The results of extreme condition test for supply cost and sales amount when the suppliers' prices jump 10 times

We use extreme condition test to build confidence in the usefulness of this framework (system dynamics and portfolio optimisation). For this purpose, we assume that two of the suppliers have the same situation in terms of supply risk indicators who are very high in price and very poor in quality, they are also highly prone to financial and production disruption. However, the third supplier has a competitive price, high quality, and very strong financial and production capability. The correct decision making in this extreme scenario is certainly clear, and it is expected to allocate whole orders to the third supplier regardless of the decision maker's risk aversion level. The result is as expected (as shown in Fig 11). It depicts that allocating the whole orders to the third supplier entails less risk and most profit and it will be the best decision for H.L and L.L risk aversion attitude. Therefore, the model passed the extreme condition test. 


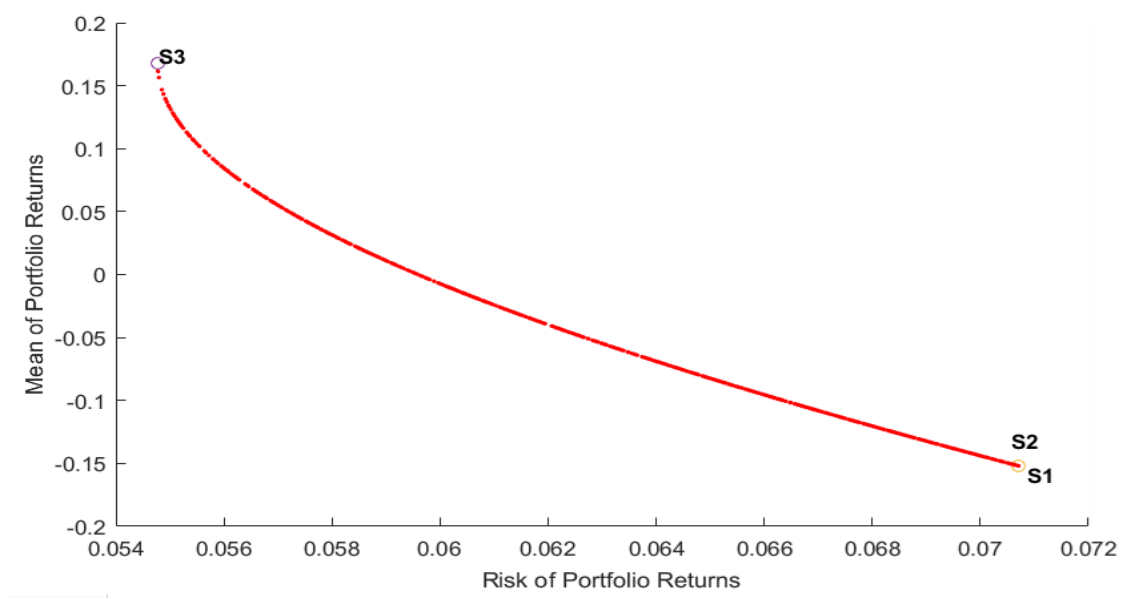

Fig 11. Order allocation in extreme condition test

\section{Conclusion and limitation}

We have developed a decision-making framework for a manufacturing supply chain consisting of I potential suppliers, one manufacturer and a product market. The aim of the model is to select suppliers and allocate orders to them to maximise the manufacturer's profit for a specific level of risk. To assess supply operation status in a timely manner, the suppliers' risk indicators are monitored by the manufacturer. The customer demand is elastic to the product quality and price, therefore, the prediction of product sales, in each period, is updated based on available data from suppliers. The significant ability of the model is employing stochastic variables for the risk indicators. This paper provides an integrated framework in which the historical data, statistical forecast, and indicators based judgmental forecast are applied.

Our proposed model for decision making is consistent with real-world decision-making problems. The framework developed is a multi-period decision-making model based on the available information and the expectations of the future. In a nutshell, this paper proposes an optimisation framework that would allow for the inclusion of the effect of supply risk in supplier selection and order allocation at the start of a period, by predicting the impact of the risks on the subsequent periods (but not necessarily doing the order allocation for the whole-time horizon). 
Our main findings are summarized as follows. By applying a system dynamics model, the dynamic relations and the feedback loops between suppliers' risks and the risks in other supply chain components are captured. The results show how the suppliers' risk indicators influence the product sales amount and consequently the manufacturer's profit. It shows how monitoring the supply risk indicators and dynamic forecast provide real-time risk monitoring capability that facilitates risk mitigation strategies in a timely manner. It enables supply chain decision makers in supplier selection and order allocation based on the updated information about suppliers' risk indicators. The result of the model shows how many orders to each supplier would maximise the manufacturer's profit for a specific level of risk. This multi-period model has been applied for both high-level risk-averse and low-level risk-averse decision makers. It shows that the manufacturer's profit would be increased, and its risks would be decreased by applying this model. However, the H.L risk-averse decision maker makes less profit and fewer risks while the L.L risk-averse decision maker makes more profit with more risks. For instance, the results of a numerical example showed that a H.L risk-averse decision maker makes a profit that is $5.4 \%$ larger than that for a L.L. risk -averse decision maker by the end of a three-year planning horizon. The profit risk for the H.L risk-averse decision maker is also $1 \%$ less than that for a L.L risk-averse decision maker at the end of the planning horizon.

Findings of this paper should be viewed in the context of the lack of empirical data to assess its application in practice. Our interviews with experts showed that many of the information required as inputs to the model are commercially sensitive and are not accessible to this research. This problem is not limited to our model, as it is a common obstacle which is stated by other authors such as [13]. To build confidence in the validity of the model, we conducted dimensional constancy, sensitivity analysis, and extreme condition tests. The outcomes of the model were consistent with the expected results. Future work can apply the framework developed to assess its reliability and suitability to different industrial contexts. 


\section{References}

1. Samsung Electronics. 2016; Available from: http://www.samsung.com.

2. Ericsson. 2000; Available from: https://www.ericsson.com/assets/local/about-ericsson/ericssonhistory/annual-report/documents/annua2000_understanding_en.pdf.

3. Gao, L., Collaborative forecasting, inventory hedging and contract coordination in dynamic supply risk management. European Journal of Operational Research, 2015. 245(1): p. 133-145.

4. Govindan, K., et al., Multi criteria decision making approaches for green supplier evaluation and selection: a literature review. Journal of Cleaner Production, 2015. 98: p. 66-83.

5. Karsak, E.E. and M. Dursun, Taxonomy and review of non-deterministic analytical methods for supplier selection. International Journal of Computer Integrated Manufacturing, 2016. 29(3): p. 263-286.

6. Deep, S., et al. An analytical literature review of risks in collaborative procurement. in The Royal Institution of Chartered Surveyors-Annual Construction, Building and Real Estate Research Conference, London, UK. Retrieved from http://www. rics. org/Documents/COBRA. 2018.

7. Hong, Z., C. Lee, and L. Zhang, Procurement risk management under uncertainty: a review. Industrial Management \& Data Systems, 2018. 118(7): p. 1547-1574.

8. Hamdi, F., et al., Optimization of a supply portfolio in the context of supply chain risk management: literature review. Journal of Intelligent Manufacturing, 2018. 29(4): p. 763-788.

9. Gao, L., et al., Dynamic Supply Risk Management with Signal-Based Forecast, Multi-Sourcing, and Discretionary Selling. Production and Operations Management, 2017. 26(7): p. 1399-1415.

10. Altug, M.S. and A. Muharremoglu, Inventory management with advance supply information. International journal of production economics, 2011. 129(2): p. 302-313.

11. Atasoy, B., R. Güllü, and T. Tan, Optimal inventory policies with non-stationary supply disruptions and advance supply information. Decision Support Systems, 2012. 53(2): p. 269-281.

12. Hu, X. and J.G. Motwani, Minimizing downside risks for global sourcing under price-sensitive stochastic demand, exchange rate uncertainties, and supplier capacity constraints. International Journal of Production Economics, 2014. 147: p. 398-409.

13. Guertler, B. and S. Spinler, Supply risk interrelationships and the derivation of key supply risk indicators. Technological Forecasting and Social Change, 2015. 92: p. 224-236.

14. Merzifonluoglu, Y., Impact of risk aversion and backup supplier on sourcing decisions of a firm. International Journal of Production Research, 2015: p. 1-25.

15. Silbermayr, L. and S. Minner, Dual sourcing under disruption risk and cost improvement through learning. European Journal of Operational Research, 2016. 250(1): p. 226-238.

16. $\mathrm{Li}, \mathrm{X}$. and $\mathrm{Y}$. Li, On the loss-averse dual-sourcing problem under supply disruption. Computers \& Operations Research, 2018. 100: p. 301-313.

17. Ruhrmann, S.H., Jan; Lanza, Gisela, Assessment of Dynamics and Risks in Supplier Selection Processes. Procedia CIRP, 2014. 25: p. 2-9.

18. Angün, E., A risk-averse approach to simulation optimization with multiple responses. Simulation Modelling Practice and Theory, 2011. 19(3): p. 911-923.

19. Sawik, T., Optimization of cost and service level in the presence of supply chain disruption risks: Single vs. multiple sourcing. Computers \& Operations Research, 2014. 51: p. 11-20.

20. Sawik, T., Selection of resilient supply portfolio under disruption risks. Omega, 2013. 41(2): p. 259-269. 
21. Sterman, J., Business Dynamics: Systems Thinking and Modeling for a Complex World. 2000: Irwin/McGraw-Hill.

22. Botha, A., J. Grobler, and V.S. Yadavalli, System dynamics comparison of three inventory management models in an automotive parts supply chain. Journal of Transport and Supply Chain Management, 2017. 11(1): p. 1-12.

23. Ghadge, A., et al., Impact of additive manufacturing on aircraft supply chain performance: $A$ system dynamics approach. Journal of Manufacturing Technology Management, 2018. 29(5): p. 846-865.

24. Größler, A., An exploratory system dynamics model of strategic capabilities in manufacturing. Journal of Manufacturing Technology Management, 2010. 21(6): p. 651-669.

25. Zhou, L., M.M. Naim, and S.M. Disney, The impact of product returns and remanufacturing uncertainties on the dynamic performance of a multi-echelon closed-loop supply chain. International Journal of Production Economics, 2017. 183: p. 487-502.

26. Udenio, M., J.C. Fransoo, and R. Peels, Destocking, the bullwhip effect, and the credit crisis: Empirical modeling of supply chain dynamics. International Journal of Production Economics, 2015. 160: p. 34-46.

27. Kumar, S. and T. Yamaoka, System dynamics study of the Japanese automotive industry closed loop supply chain. Journal of Manufacturing Technology Management, 2007. 18(2): p. 115-138.

28. Corinna Cagliano, A., et al., Using system dynamics in warehouse management: a fast-fashion case study. Journal of Manufacturing Technology Management, 2011. 22(2): p. 171-188.

29. Kochan, C.G., et al., Impact of cloud-based information sharing on hospital supply chain performance: A system dynamics framework. International Journal of Production Economics, 2018. 195: p. 168-185.

30. Özbayrak, M.P., Theopisti C.; Akgun, Melek, Systems dynamics modelling of a manufacturing supply chain system. Simulation Modelling Practice and Theory, 2007. 15(10): p. 1338-1355.

31. Golroudbary, S.R. and S.M. Zahraee, System dynamics model for optimizing the recycling and collection of waste material in a closed-loop supply chain. Simulation Modelling Practice and Theory, 2015. 53: p. 88-102.

32. Swinerd, C. and K.R. McNaught, Design classes for hybrid simulations involving agent-based and system dynamics models. Simulation Modelling Practice and Theory, 2012. 25: p. 118-133.

33. Hsieh, Y.-H. and Y.-H. Chou, Modeling the impact of service innovation for small and medium enterprises: A system dynamics approach. Simulation Modelling Practice and Theory, 2018. 82: p. 84-102.

34. Sudarto, S., K. Takahashi, and K. Morikawa, Efficient flexible long-term capacity planning for optimal sustainability dimensions performance of reverse logistics social responsibility: A system dynamics approach. International Journal of Production Economics, 2017. 184: p. 179-192.

35. Rowzan, S.M., Designing a hybrid system dynamic model for analyzing the impact of strategic alignment on project portfolio selection. Simulation Modelling Practice and Theory, 2018.

36. Markowitz, H., Portfolio selection. The journal of finance, 1952. 7(1): p. 77-91.

37. Hosseininasab, A. and A. Ahmadi, Selecting a supplier portfolio with value, development, and risk consideration. European Journal of Operational Research, 2015. 245(1): p. 146-156.

38. Abdollahi, M., M. Arvan, and J. Razmi, An integrated approach for supplier portfolio selection: Lean or agile? Expert Systems with Applications, 2015. 42(1): p. 679-690. 
39. Sawik, T., A portfolio approach to supply chain disruption management. International Journal of Production Research, 2017. 55(7): p. 1970-1991.

40. Sawik, T., Selection of Dynamic Supply Portfolio, in Supply Chain Disruption Management Using Stochastic Mixed Integer Programming. 2018, Springer International Publishing: Cham. p. 43-67.

41. Mokhtar, S., et al., A Novel Decision-Making Approach for Supplier Selection under Risks, in Computer Aided Chemical Engineering, A. Espuña, M. Graells, and L. Puigjaner, Editors. 2017, Elsevier. p. 1267-1272.

42. Altman, E.I., Predicting financial distress of companies: revisiting the Z-score and ZETA models. Stern School of Business, New York University, 2000: p. 9-12.

43. Varian, H.R., Intermediate Microeconomics: A Modern Approach: Ninth International Student Edition. 2014: WW Norton \& Company.

44. J.Fabozzi, F., Simulation and Optimization in finance. 2010: John Wiley \& Sons.

45. PACIFIC Exchange Rate Service. [cited 2019; Available from: http://fx.sauder.ubc.ca/.

46. Barlas, Y., Formal aspects of model validity and validation in system dynamics. System Dynamics Review: The Journal of the System Dynamics Society, 1996. 12(3): p. 183-210.

\section{Appendix A:}

Table S1

The parameters and equations applied in the simulation model

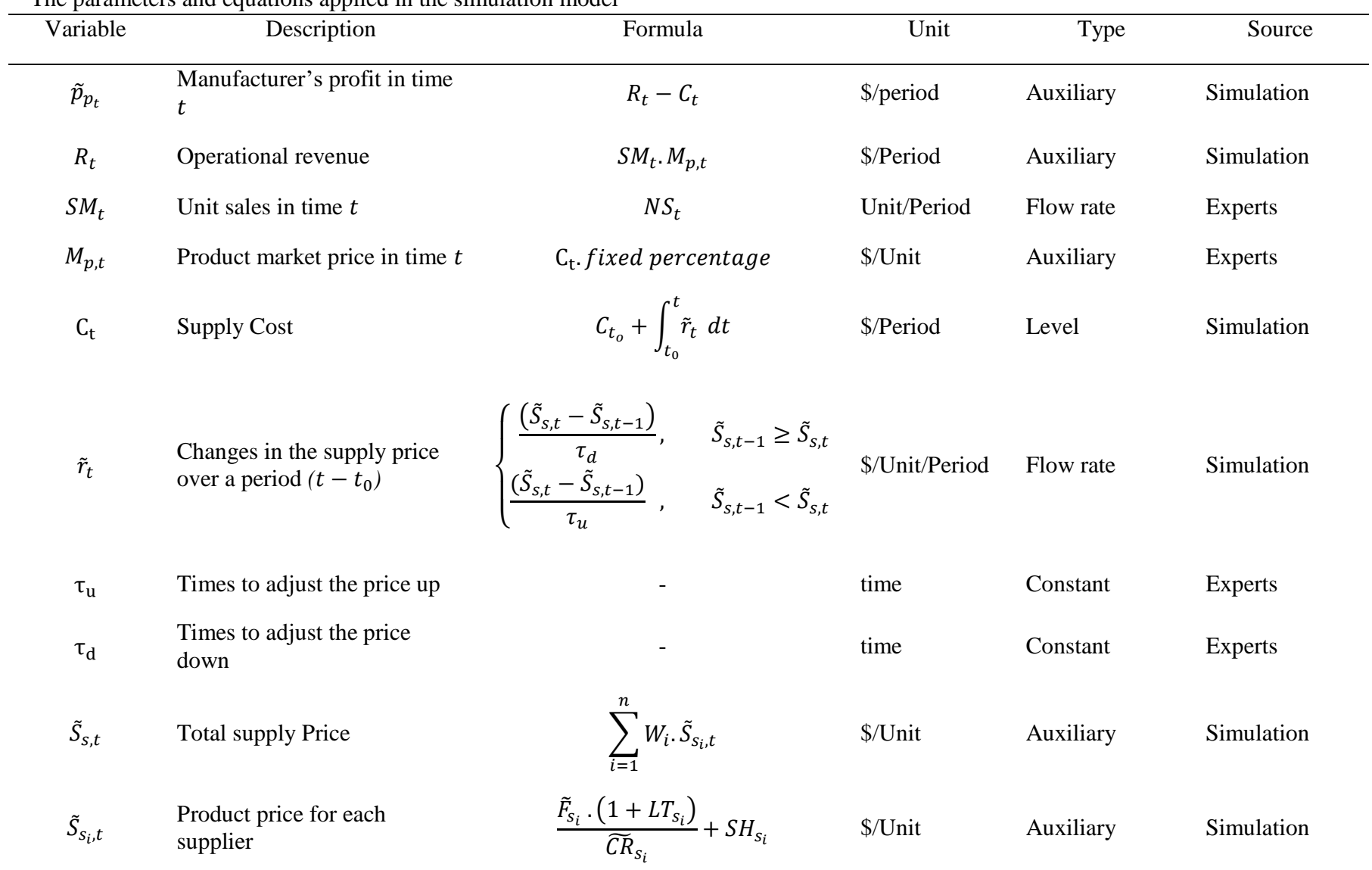




\begin{tabular}{|c|c|c|c|c|c|}
\hline$\widetilde{C R_{S_{l}}}$ & $\begin{array}{l}\text { Fluctuation in currency } \\
\text { exchange rate for each } \\
\text { supplier }\end{array}$ & - & $\begin{array}{l}\text { Local } \\
\text { currency } \\
\text { /manufacturer } \\
\text { currency }\end{array}$ & $\begin{array}{l}\text { Random } \\
\text { variable with } \\
\text { specific mean } \\
\text { and standard } \\
\text { deviation }\end{array}$ & $\begin{array}{l}\text { Oneline } \\
\text { website }\end{array}$ \\
\hline$L T_{s_{i}}$ & Local tax for each supplier & a fraction of $\widetilde{F}_{s_{i}}$ & \$/Unit & Constant & $\begin{array}{l}\text { Weights from } \\
\text { experts }\end{array}$ \\
\hline$\tilde{F}_{S_{i}}$ & $\begin{array}{l}\text { Fixed cost of production for } \\
\text { each supplier }\end{array}$ & - & $\begin{array}{l}\text { Local } \\
\text { Currency/Unit }\end{array}$ & $\begin{array}{l}\text { Random } \\
\text { variable with } \\
\text { specific mean } \\
\text { and standard } \\
\text { deviation }\end{array}$ & $\begin{array}{l}\text { Supplier } \\
\text { database }\end{array}$ \\
\hline$S H_{i}$ & $\begin{array}{l}\text { Shipping cost for each } \\
\text { supplier }\end{array}$ & - & \$/unit & Constant & $\begin{array}{l}\text { Supplier } \\
\text { database }\end{array}$ \\
\hline$B_{t}$ & Backlog in time $t$ & $B_{t_{0}}+\int_{t_{0}}\left(N S_{t}-S M_{t}\right) d t$ & Unit & Level & Simulation \\
\hline$N S_{t}$ & $\begin{array}{l}\text { Received amount of supply at } \\
\text { time } t\end{array}$ & $N S_{t}=D P_{t}-Q_{s, t}-D_{t}$ & Unit/Period & Flow rate & Simulation \\
\hline$D P_{t}$ & Desired amount of production & a fraction of $D_{t}$ & Unit/Period & Auxiliary & Experts \\
\hline$Q_{s, t}$ & Number of supply defects & $\sum_{i} w_{i} \cdot D P_{t} \cdot Q_{s_{i}, t}$ & Unit/Period & Auxiliary & Simulation \\
\hline$D_{s, t}$ & $\begin{array}{l}\text { Amount of delayed orders } \\
\text { which are not delivered to the } \\
\text { manufacturer in time } t\end{array}$ & $\sum_{i}^{n} w_{i} \cdot D P_{t} \cdot\left(P r_{s_{i}, t}+\widetilde{S H D}_{s_{i}}\right)$ & Unit/Period & Auxiliary & Simulation \\
\hline$Q_{s_{i}, t}$ & $\begin{array}{l}\text { Percentage of supply defects } \\
\text { per order for supplier } i\end{array}$ & - & $\%$ & Constant & $\begin{array}{l}\text { Supplier } \\
\text { database }\end{array}$ \\
\hline$F D_{s_{i}, t}$ & Financial instability & 1/Altman z-score & rate & & $\begin{array}{l}\text { Altman z- } \\
\text { score }\end{array}$ \\
\hline$R_{s_{i}, t}$ & $\begin{array}{l}\text { Return on asset for each } \\
\text { supplier in period } t\end{array}$ & - & rate & Constant & $\begin{array}{l}\text { Supplier } \\
\text { database }\end{array}$ \\
\hline$A_{s_{i}, t}$ & $\begin{array}{l}\text { Asset turnover ratio for each } \\
\text { supplier }\end{array}$ & - & rate & Constant & $\begin{array}{l}\text { Supplier } \\
\text { database }\end{array}$ \\
\hline$E_{s_{i}, t}$ & $\begin{array}{l}\text { Equity to debt ratio for each } \\
\text { supplier }\end{array}$ & - & rate & Constant & $\begin{array}{l}\text { Supplier } \\
\text { database }\end{array}$ \\
\hline$R E_{S_{i}, t}$ & $\begin{array}{l}\text { Retained earnings to total } \\
\text { asset ratio for each supplier }\end{array}$ & - & rate & Constant & $\begin{array}{l}\text { Supplier } \\
\text { database }\end{array}$ \\
\hline$W C_{s_{i}, t}$ & $\begin{array}{l}\text { Working capital to total asset } \\
\text { ratio for each supplier }\end{array}$ & - & rate & Constant & $\begin{array}{l}\text { Supplier } \\
\text { database }\end{array}$ \\
\hline$P D_{s_{i}}$ & Production instability & $\begin{array}{c}1-\left(0.3 . P C_{i}+0.2 . Q C_{i}+0.2 . P F_{i}\right. \\
\left.+0.3 \cdot P T_{i}\right)\end{array}$ & rate & Auxiliary & Simulation \\
\hline$P C_{i}$ & Production capacity & - & rate & Constant & $\begin{array}{l}\text { Weights from } \\
\text { experts }\end{array}$ \\
\hline$Q C_{i}$ & Quality control system & - & rate & Constant & $\begin{array}{l}\text { Weights from } \\
\text { experts }\end{array}$ \\
\hline
\end{tabular}




\begin{tabular}{|c|c|}
\hline$P F_{i}$ & Production facility \\
\hline$P T_{i}$ & Production technology \\
\hline$S H D_{S_{i}}$ & Shipping delays for supplier i \\
\hline$P r_{s_{i}, t}$ & $\begin{array}{l}\text { Supplier disruption } \\
\text { probability }\end{array}$ \\
\hline$D_{t}$ & Product market demand \\
\hline$\eta$ & Price elasticity of demand \\
\hline$\gamma$ & $\begin{array}{l}\text { The quality elasticity of } \\
\text { demand }\end{array}$ \\
\hline$W_{i}$ & Weight of each supplier \\
\hline
\end{tabular}

\begin{tabular}{|c|c|c|c|}
\hline - & rate & Constant & $\begin{array}{l}\text { Weights from } \\
\text { experts }\end{array}$ \\
\hline- & rate & Constant & $\begin{array}{l}\text { Weights from } \\
\text { experts }\end{array}$ \\
\hline- & $\%$ & $\begin{array}{l}\text { Random } \\
\text { variable with } \\
\text { specific mean } \\
\text { and standard } \\
\text { deviation }\end{array}$ & $\begin{array}{l}\text { Supplier } \\
\text { database }\end{array}$ \\
\hline$F D_{s_{i}, t} \cdot P D_{s_{i}}$ & rate & Auxiliary & Simulation \\
\hline$D_{t-1} \cdot e^{\eta \cdot \ln } \frac{\tilde{S}_{p, t}}{\tilde{S}_{p, t-1}} \cdot e^{\gamma \cdot \ln \frac{Q_{s, t}}{Q_{s, t-1}}}$ & Unit/Period & Auxiliary & Simulation \\
\hline- & rate & Constant & Experts \\
\hline- & rate & Constant & Experts \\
\hline- & $\%$ & Constant & Optimisation \\
\hline
\end{tabular}




\section{Appendix B:}

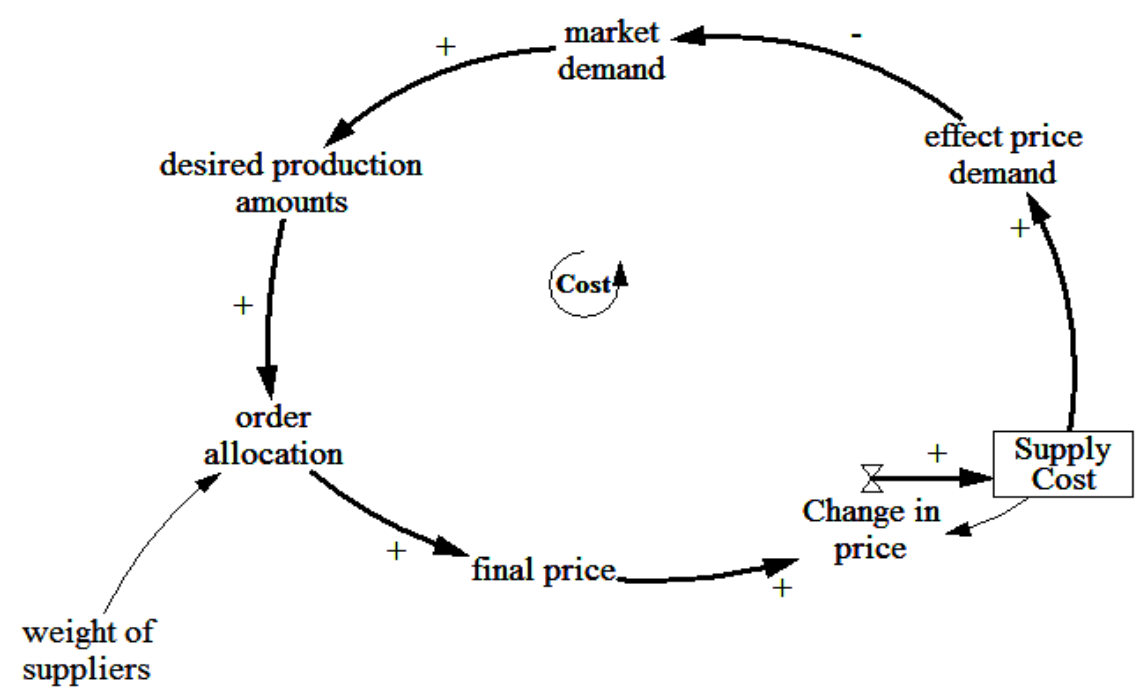

Fig. S1. supply cost diagram

Fig. S1 depicts the loop that controls supply cost. It shows that when a supplier's final price increases, the supply cost for manufacturer increases, which in turn has a counteractive effect on product demand: when the supply cost increases, the product demand decreases. When the product demand decreases, so does the desired production amounts for the manufacturer. The supplier allocation weights, derived from the portfolio optimisation model, influences manufacturing supply cost. The loop is negative as it controls the supply cost. However, it does not mean that this loop always leads to a decrease in cost; it depends on the result of portfolio optimization, which in turn is influenced by the decision maker's risk propensity. 


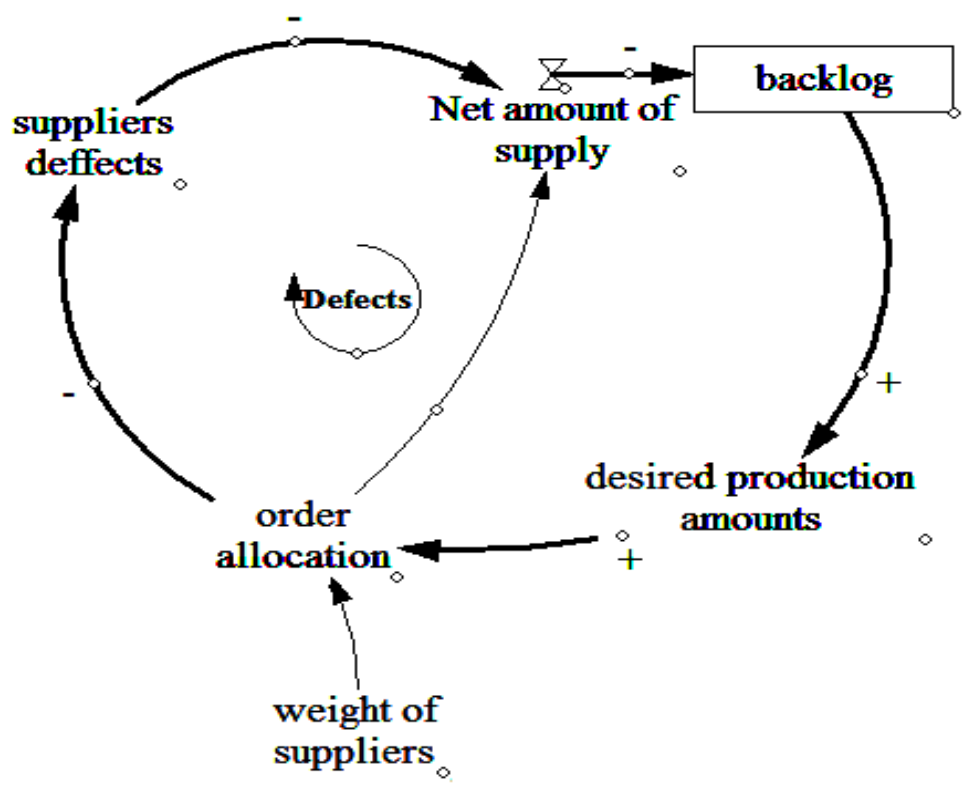

Fig. S2. supply defects diagram

Fig. S2, represents the loop that controls supply defects received from auppliers. It shows that the supply defects have a counteractive effect on the amount of supply. As such, when the supply amount decreases, the backlog increases. The backlog influences the desired production amounts in the same direction. When backlog increases, the desired production increases to compensate the backlog orders. The desired production amounts in turn influences the amounts of orders allocated to the suppliers. The supplier allocation weights, resulted from the portfolio optimisation model, influences the supply defects by weighting the suppliers. However, it doesn't mean that necessarily the supply defect will be reduced, the result depends on the decision makers propensity of risk. This negative loop controls the supply defects. 


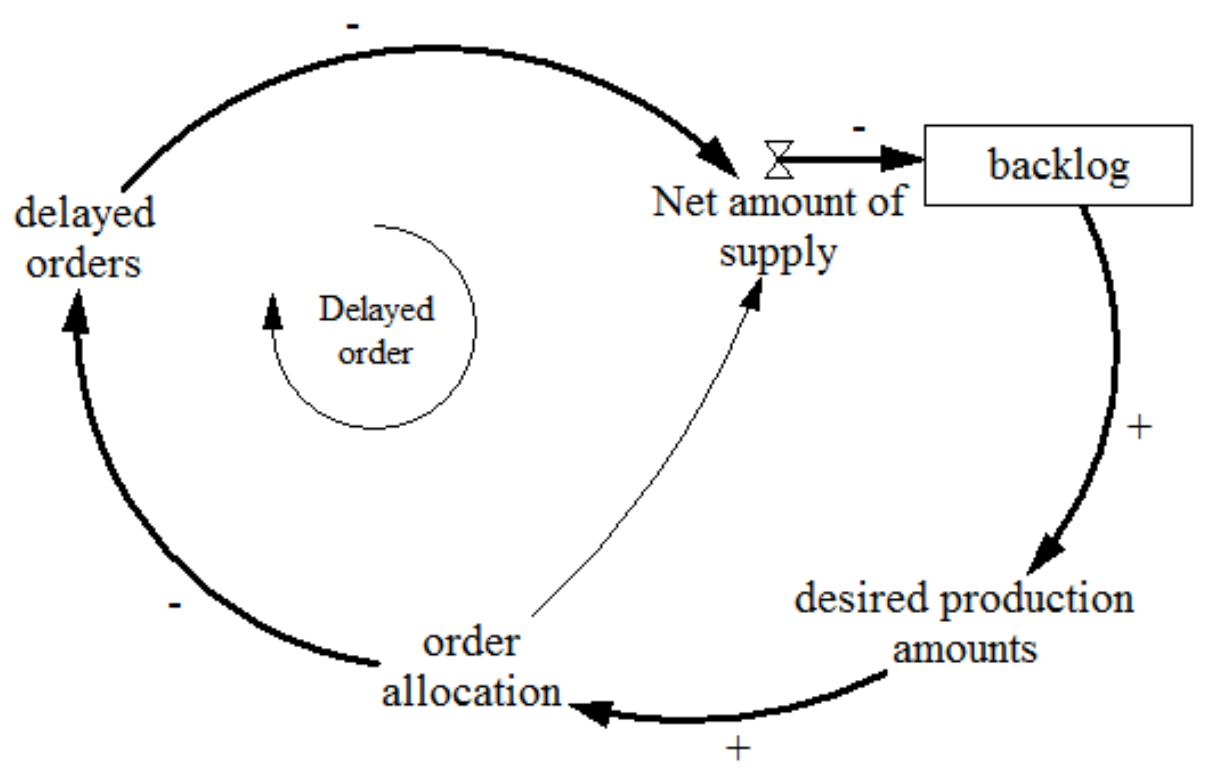

Fig S3. delayed orders diagram

Fig. S3, denotes the loop that controls the supply delayed orders. It shows that when the delayed supplies increases, then the total amount of supply received by the manufacturer decreases. The more amounts of supply leads to less amounts of the backlog. Therefore, a growth in backlog amount encourages the manufacturer to produce more; then the backlog changes the desired production amount in the same direction. When the desired production amount increases, more orders will be allocated to the suppliers. The optimal order will be allocated to the suppliers based on the optimal weights of the supplier as the output of the optimisation to control the delayed supply orders. The order allocation to the suppliers depends on the risk propensity of the decision maker. This loop is a negative loop as it is a controlling loop for delayed orders. 